THE VALUE OF COMMUNITY HEALTH NURSING:

A PHENOMENOLOGICAL STUDY OF THE

PERCEPTIONS OF COMMUNITY HEALTH NURSES

by

BEVERLY DIANE LEIPERT

B.A., The University of Saskatchewan, 1977

B.S.N., The University of Saskatchewan, 1977

A THESIS SUBMITTED IN PARTIAL FULFILMENT OF

THE REQUIREMENTS FOR THE DEGREE OF

MASTER OF SCIENCE IN NURSING

in

THE FACULTY OF GRADUATE STUDIES

School of Nursing

We accept this thesis as conforming to the required standard

THE UNIVERSITY OF BRITISH COLUMBIA

September, 1992

(C) Beverly Diane Leipert, 1992 
In presenting this thesis in partial fulfilment of the requirements for an advanced degree at the University of British Columbia, I agree that the Library shall make it freely available for reference and study. I further agree that permission for extensive copying of this thesis for scholarly purposes may be granted by the head of my department or by his or her representatives. It is understood that copying or publication of this thesis for financial gain shall not be allowed without my written permission.

Department of Dchod o Nunebro

The University of British Columbia Vancouver, Canada

Date September $28,1992$. 
ABSTRACT

This study explores and describes the value of community health nursing from the perspective of community health nurses. The phenomenological method as defined by Colaizzi (1978) guided this exploration. Eleven community health nurses from the health department of a large urban center participated in the study. Each nurse held a baccalaureate degree in nursing and had a minimum of two years of community health nursing experience in preventive health care programs.

The researcher collected the data through a series of interviews. Each nurse was interviewed at least twice. Interviews were taped and transcribed verbatim. Interviews were analyzed to determine areas for clarification and exploration, to discover themes, and to determine data saturation.

From continuous comparative analysis of the data, five themes emerged: (1) the value of activities in community health nursing, (2) the value of the purposes of community health nursing, (3) the value of prerequisites for community health nursing, (4) the value of the visibility of community health nursing, and (5) the value of community health nursing as the way to the future in health care.

In the first theme, participants primarily valued multiple and varied activities which enabled and empowered clients to make informed health care decisions, choices, and actions. Subthemes included collaborative activities and autonomy. 
The second theme described the purposes of community health nursing as they relate to various clients, the context of practice, and the holistic vision of health.

The third theme described the value of certain prerequisites for community health nursing. Participants identified two categories of prerequisites - knowledge, and certain personal qualities and attitudes.

In the fourth theme, the value of the visibility of community health nursing, subthemes included: awareness, valuing, and effective use of community health nursing services by others, and political visibility.

In the fifth theme, community health nursing as the way to the future in health care, subthemes included: the preventive focus and cost-effectiveness bases of community health nursing, and the value of research.

The findings of this study have implications for community health nursing practice, administration, education, and research. In nursing practice, community health nursing roles and activities must be more clearly defined and promoted so that the value of community health nursing can be more fully realized. Administrators must support nursing staff and actively facilitate effective community health nursing practice.

Nursing education must prepare professional nursing practitioners who have the knowledge and the ability to successfully practice community health nursing. All nurses must be encouraged in their education to appreciate the value of community health nursing so that the quality and quantity of community health care is facilitated in all nursing settings. 
All aspects of professional nursing - practice, administration, education, and research - must promote community health nursing research. Further research is required into the value of community health nursing from a variety of perspectives, such as the perspectives of nurses in other settings, clients, and colleagues. Research into these perspectives will likely achieve a clearer consensus of the value of community health nursing, and foster present and future community health nursing endeavors. As a consequence, the health care of Canadians could be addressed more effectively and efficiently. 
TABLE OF CONTENTS

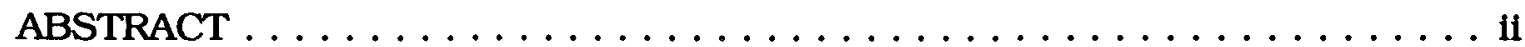

TABLE OF CONTENTS $\ldots \ldots \ldots \ldots \ldots \ldots \ldots \ldots \ldots \ldots \ldots \ldots$

ACKNOWLEDGEMENTS $\ldots \ldots \ldots \ldots \ldots \ldots \ldots \ldots \ldots \ldots \ldots \ldots \ldots$ vii

DEDICATION $\ldots \ldots \ldots \ldots \ldots \ldots \ldots \ldots \ldots \ldots \ldots \ldots \ldots \ldots \ldots \ldots$

\section{CHAPTER 1: INTRODUCTION}

Background to the Problem $\ldots \ldots \ldots \ldots \ldots \ldots \ldots$

Problem Statement . . . . . . . . . . . . . . . . . 6

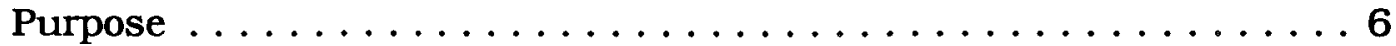

Conceptualization of the Study $\ldots \ldots \ldots \ldots \ldots \ldots \ldots \ldots \ldots \ldots \ldots \ldots \ldots$

Research Question ........................ 9

Introduction to the Method . . . . . . . . . . . . . . . . 9

Theoretical Significance of the Study ............... 10

Practical Significance of the Study . . . . . . . . . . . . 11

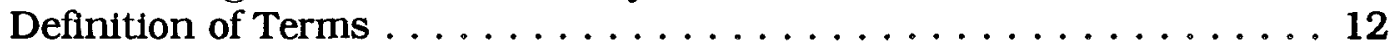

Assumptions ........................ 13

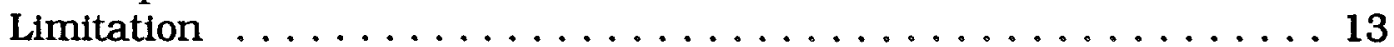

CHAPTER 2: CRITICAL REVIEW OF SELECTED LITERATURE

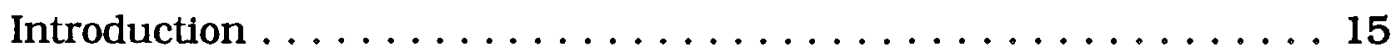

Community Health Nurses' Perspectives . . . . . . . . . . . 16

Community Health Nursing Roles and Activities . . . . . . . . . 18

Community Health Nursing and the Nursing Profession . . . . . . 20

Trends . . . . . . . . . . . . . . . . . . . . . 22

Trends in Nursing Education . . . . . . . . . . . 22

Trends in Nursing Practice . . . . . . . . . . . . . 25

Trends in Nursing Administration . . . . . . . . . . 27

Trends in Nursing Research . . . . . . . . . . . . . . . 29

Community Health Nursing and the Canadian Public ........ 31

\section{CHAPTER 3: METHODOLOGY}

The Phenomenological Method $\ldots \ldots \ldots \ldots \ldots \ldots . \ldots \ldots$

Sample Selection, Recruitment, and Size . . . . . . . . . . . . 35

Characteristics of the Participants . . . . . . . . . . . . . 42

Ethical Considerations ...................43

Data Collection ...................... 43

Data Analysis . . . . . . . . . . . . . . . . . . . 56

Reliability and Validity . . . . . . . . . . . . . . 62 


\section{CHAPTER 4: PRESENTATION AND DISCUSSION OF THE FINDINGS}

Theme One: The Value of Activities in Community Health Nursing . . 69 Subtheme One: Collaborative Activities . . . . . . . . . . 70

Subtheme Two: Autonomy . . . . . . . . . . . . . . 74

Theme Two: The Value of the Purposes of Community Health

Nursing ........................... 77

Subtheme One: The Client .............. 77

Subtheme Two: Context of Practice . . . . . . . . . . . 79

Subtheme Three: Health . . . . . . . . . . . . . . 81

Theme Three: The Value of Prerequisites for Community Health

Nursing . . . . . . . . . . . . . . . . . . 85

Subtheme One: Knowledge . . . . . . . . . . . . . . . 85

Subtheme Two: Personal Qualities and Attitudes . . . . . . . 90

Theme Four: The Value of the Visibility of Community Health

Nursing . . . . . . . . . . . . . . . . 97

Subtheme One: Others' Awareness and Valuing . . . . . . . 98

Subtheme Two: Political Visibility . . . . . . . . . . . . . 105

Theme Five: The Value of Community Health Nursing as the Way

to the Future . . . . . . . . . . . . . . . . . . . . . . . 109

Subtheme One: Prevention and Cost-effective Bases . . . . . 109

Subtheme Two: Research . . . . . . . . . . . . . . 112

CHAPTER FIVE: SUMMARY, CONCLUSIONS, AND IMPLICATIONS FOR NURSING

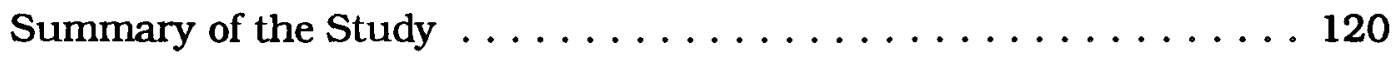

Conclusions . . . . . . . . . . . . . . . . . . 122

Implications . . . . . . . . . . . . . . . . . . . . 124

Implications for Community Health Nursing Practice . . . . . . 125

Implications for Community Health Nursing Administration . 135

Implications for Community Health Nursing Education . . . . 139

Implications for Community Health Nursing Research . . . . . 146

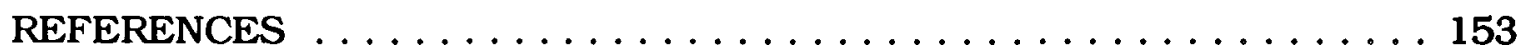

\section{APPENDICES}

Appendix A: Information Letter to Community Health Nurses . . . . 160

Appendix B: Consent to Participate . . . . . . . . . . . . . 161

Appendix C: Trigger Questions . . . . . . . . . . . . . . . . 162 


\section{ACKNOWLEDGEMENTS}

For their time and expertise in guiding me through this research project, I wish to thank my thesis advisors, Professor Ray Thompson, Chairperson, and Professor Wendy Hall. Our critical interactions helped me to reach a degree of educational excellence that I would not otherwise have achieved. I also thank Professor Linda Leonard for reading my thesis and providing critical analysis of it prior to its completion.

From my friends and colleagues, Jaye Kerzner and Ellen Roberts, I received much support and empathetic understanding. I thank them for being there for me, in good times and in bad. I also thank my spouse, Dr. Russell Cornett, for his love and support. His objective perspective, empathy, and friendship were invaluable to the completion of this project.

As for the as yet unsung heroines of this thesis: I wish to thank the eleven community health nurses who participated in this study and who gave so generously of their time and expertise. I thank each of them for allowing me to share some of their personal perspectives about community health nursing. Their forthright, insightful, and articulate views contributed significantly to the understanding of community health nursing and its value. 


\section{DEDICATION}

I dedicate this thesis to my late mother, Irene Leipert. Her love and support throughout the years are the true foundations of my educational achievements. Although she began this project with me, sadly she could not be with me at its completion. She would have been so proud. 


\section{CHAPTER 1: INTRODUCTION}

\section{Background to the Problem}

For every dollar Canadians spend on health care, less than a nickel goes toward health promotion and disease prevention (Rachlis \& Kushner, 1989). British Columbia, for example, allocated $6.7 \%$ of the $1989 / 90$ provincial health care budget to community and family health services, while it allocated $48.3 \%$ to hospital programs (Jansen, 1990). Even so, hospital-based acute care programs are neither adequately nor appropriately meeting the health care needs of the public (Rachlis \& Kushner, 1989).

Recent reports and publications (Epp, 1986; Lalonde, 1974; World Health Organization, Health \& Welfare Canada, \& Canadian Public Health Association, 1986) have affirmed that preventive health care concepts and practices are vital to the health of Canadians. In British Columbia, the report of the Royal Commission on Health Care and Costs (1991) recommended major shifts in priorities and funding away from acute care and toward the prevention of illness and the promotion of health. The Royal Commission recommended implementing these changes through more support on the part of public health personnel for public health concerns, the establishment and use of indicators to measure the effects of public health policies, programs, and interventions, and the expansion of community health services. Preventive health care, then, must receive equal if not greater emphasis than acute care in the present health care system. Community health nurses are key players in preventive care, and play a major role in promoting preventive care. However, community 
health nurses have been minimally proactive in advancing preventive care in Canada (Clarke, Beddome, \& Whyte, 1990).

Matuk \& Horsburgh (1989) have suggested five areas that affect the ability and motivation of community health nurses to advance preventive health care: lack of role clarity, lack of recognition of the value of preventive services by governments and the public, lack of recognition of community health nursing as a subspecialty within nursing, lack of political involvement by nurses, and lack of an adequate supply of well-prepared community health nurse educators and administrators. Consequently, community health nurses may be unclear about the value of their roles, and about the values that they should advance. For example, lack of role clarity makes it difficult for nurses to know what to value and, therefore, what values to prize and promote. A lack of qualified community health nursing educators contributes to lack of role clarity beginning in baccalaureate nursing programs. Students may not develop the specialized skills and a clear conception of the roles of community health nursing in such educational programs. Consequently, they tend to turn to other health care providers for guidance, and the community health nursing role is weakened (Matuk \& Horsburgh, 1989).

In the practice arena, there is a lack of effective community health nursing administrators with sufficient leadership and management skills to influence the quality and directions of the profession (Matuk \& Horsburgh, 1989). Administrators must effectively define the scope of community health nursing practice within the boundaries of program priorities, staff needs, geographical responsibilities, and budget provisions. In addition, community 
health nursing administrators must actively initiate submission of sound program and budget proposals to the Ministry of Health, rather than simply waiting for the government to allocate monies. Administrative deficits in these areas have implications for the choosing, prizing, and activation of values by community health nursing staff.

Matuk and Horsburgh (1989) have suggested that community health nurses are in a key position to exercise a primary role in moving toward a more preventive health system. To assume this leadership, however, they must be able to successfully articulate and demonstrate the value of preventive services not only to themselves, but also to the rest of the Canadian populace. This leadership requires that community health nurses know the value of their specialty within nursing, and be prepared to promote this value within the political realities of their agencies and the health care system. In addition, Matuk and Horsburgh (1989) have encouraged community health nurses to develop political strategies through networking, community and government involvement in policy making, and educating the public and policy makers. These factors require that community health nurses be clear about the values they choose, prize, and are committed to in their practice.

Another factor that may contribute to inaction on the part of community health nurses may be that nurses may be initially motivated to select community health nursing due to its appealing schedule - no shift work and weekends off - and not because of a personal understanding of or commitment to the value of this field of nursing. Also, the motivation of community health nurses to enact community health nursing values may be eroded by others 
such as community health nursing colleagues, supervisors, and clients who do not understand or hold similar values. These factors would make it difficult for community health nurses to identify what the value of community health nursing is, or to maintain and act on the community health nursing values they do hold. If they do not know the value of community health nursing or find that this value is not supported or is undermined, community health nurses would find it difficult to be committed to this value. As a consequence, since actions are based on values (Steele \& Harmon, 1983), community health nurses may not be proactive in advancing community health nursing if their commitment to community health nursing values is not present, is weakened, or is not supported. In order to meet these challenges and advance community health nursing and preventive care, community health nurses must first identify what they value about community health nursing so that they can effectively promote these values to others.

It has been suggested that the very survival of community health nursing has been jeopardized by perceptions of undervaluing on the part of community health nurses (Chavigny \& Kroske, 1983; Matuk \& Horsburgh, 1989; McCreight, 1989). Chavigny and Kroske (1983) have stated that the community health nursing specialty has been actively declining for over a decade. These authors suggest three factors that have contributed to this crisis situation are fragmentation of services, deficits in educational preparation, and role confusion.

Fragmentation of community health nursing services has occurred as a result of community health nurses' open attitudes to multidisciplinary 
cooperation. In some instances, community health nursing roles and responsibilities such as health education, school counselling, and home visits have been delegated to other fields of nursing or other disciplines, or are not enacted at all. Problems in educational preparation of community health nurses have occurred as a result of a variety of factors. Some of these factors include the undervaluing of community health nursing content within the nursing curriculum, the integration of specialized community health nursing roles into the curriculum, and the emphasis on acute care rather than disease prevention and health promotion concepts within the curriculum. These factors and others within nursing education contribute to a lack of clarity about the substance and value of community health nursing, particularly to new community health nurse practitioners.

Chavigny and Kroske (1983) state that role confusion is likely the most salient problem of community health nursing today. These authors believe that unless we can define the roles and responsibilities of community health nurses, we cannot set priorities on activities reflecting their special skills. Because the value of community health nursing has implications for the roles of community health nurses, the decline in this nursing practice is at least partially due to a lack of clarity about its value.

Matuk and Horsburgh (1989) have also recognized that the status of community health nursing in Canada is in jeopardy. In order to advance the status of community health nursing and rebuild its importance as a specialty, they have suggested that community health nurses need to acknowledge and promote the value of their services. 


\section{Problem Statement}

The problem that this study seeks to address is the lack of knowledge about the values community health nurses hold in relation to community health nursing. Since no literature was found that directly and substantially addressed this problem, knowledge of these perceptions remains unclear.

\section{Purpose}

The purpose of this study is to explore and describe from the perspective of experienced community health nurses, what community health nurses value about community health nursing.

\section{Conceptualization of the Study}

This study is conceptualized from the author's experiences in nursing, and from theoretical perspectives derived from values clarification literature. Ten years experience as a community health nurse and four years experience as a hospital nurse increased the author's interest in exploring the perceptions of the value of community health nursing.

As a community health nurse in a rural setting, the author experlenced two strikes during which all community health nursing services were withdrawn. To the dismay of the community health nurses involved, the services that were withdrawn seemed not to be missed by the public. This led to questions about what the Canadian public thought about the value of community health nursing, and these questions stimulated the author and other community health nurses to think about their own valuing of community health nursing. Since our clients, the Canadian public, did not seem to value our services, we began to question the worth of these services as well. As a 
hospital nurse in an urban setting, the author encountered the view that hospital nursing, not community health nursing, was "real" nursing.

The values expressed about community health nursing by these and other groups caused the author and other community health nurses to reflect upon their own valuing of community health nursing. We felt that much of our work was not understood or valued by others, most notably by clients and nursing colleagues in other fields of practice. This perception caused us to feel less motivated and able to advance community health nursing and preventive health care. There was also the perception on the part of community health nurses that the need existed for more active education and promotion of community health nursing concepts and services so as to better inform others about the value of their work.

Concepts from values clarification theory are useful in addressing the problem of this study. Values clarification is a dynamic process that facilitates decision-making and assists individuals to become conscious of the values and motivations that guide their actions (Steele \& Harmon, 1983). According to Steele and Harmon (1983), an individual first chooses values, then prizes these values, and then acts upon these values. Each of these three phases choosing, prizing, acting - has distinct steps (Raths, Harmin, \& Simon, 1966). In the value choosing phase, an individual chooses values freely from alternatives, and thoughtfully considers the consequences or outcomes of each alternative. In the prizing phase, the individual cherishes the chosen value, is happy with the choice, integrates the value into the individual's value system, and is willing to make the value known to others. In the acting phase, the 
individual integrates the value into the life style. Community health nurses, for example, choose and prize certain values as a result of their education and experience. As a consequence, community health nurses integrate these values into their professional life, and base decisions and actions on these values. These values, then, become part of the decision-making process and motivate the nurse to action.

The values held by health care providers strongly influence their commitment to preventive health care (Steele \& Harmon, 1983). However, many factors may affect the choosing, prizing, and activation of values by community health nurses, and consequently their commitment to preventive health care. Some of these factors include health care policies, financial constraints, and the value placed on community health nursing and preventive care by colleagues and by society. These factors may not make explicit, may not support, or may militate against the value of community health nursing. If this happens, community health nurses may not be aware of or be committed to the value of their practice. This lack of awareness of and commitment to the value of community health nursing could undermine the nurses' choosing, prizing, and activation of values central to community health nursing and preventive care.

Because no two individuals have the same life experiences, no two value systems are exactly the same. However, similarities in value systems may occur within a group, for example the group of community health nurses. Rokeach (1973) has identified some assumptions that underly all values. These assumptions are: (a) the total number of values that a person possesses is 
relatively small, (b) all persons everywhere possess the same values but to differing degrees, and (c) the antecedents of human values can be traced to culture, society, institutions, and personality. As a consequence, community health nurses should have a relattvely small number of common values. Community health nurses may attach differing importance to core values. These values will be a result of the nurse's culture (personal and professional), society (Canadian society, for example), institutions (educational and religious institutions, for example), and the nurse's own personality. The nature and prizing of these values form the basis of each community health nurse's motivations, decisions, and actions.

Values clarification theory points out the importance of values in decision-making and action-taking. As a consequence, values clarification theory provides a framework for examining the values held by community health nurses.

\section{Research Question}

The research question that this study addresses is: From the perspective of experienced community health nurses, what do community health nurses value about community health nursing?

\section{Introduction to the Method}

This study uses the phenomenological method to address the research question. The aim of phenomenology is to describe lived experience through attention to the perceived world of the participants (Oiler, 1986). This perceived world is accessed through in depth interviews and analyses of these interviews 
to determine meaning and common themes that describe the lived experience of the participants (Colaizzi, 1978).

Phenomenology has been selected as an appropriate method for this study for two reasons. First, the purpose of the study is to explore and describe what community health nurses value about community health nursing. This description is derived from the experiences and perceptions of those nurses who have "lived" or practised community health nursing. Phenomenology in its emphasis upon lived experience fosters a beginning and enriched understanding of community health nurses' perspectives. In addition, since little research has been done in this area, such enriched understanding is a reasonable beginning step in investigating the phenomenon.

Second, the phenomenological approach allows for dialogical interaction between the researcher and the research subject in a trusting relationship, not unlike a therapeutic relationship (Colaizzi, 1978). As Uustal (1977) notes, dialogue that pertains to values can be therapeutic and result in personal and professional growth. The phenomenological method can foster such growth for both the researcher and the research subjects. The phenomenological method therefore, can effectively address the research question and facilitate understanding and growth for individuals involved in the study.

\section{Theoretical Significance of the Study}

Knowledge derived from this study would be of theoretical significance in a number of areas. This study could contribute to the understanding of community health nurses' personal and professional values. Since these values form the basis for decision-making and action-taking (Steele \& Harmon, 1983), 
knowledge of these values could enhance an understanding of the motivations and abilities of community health nurses to contribute to and advance their field of nursing. Finally, this study could provide theoretical evidence that could form the basis for further investigations in community health nursing. For example, further research could investigate whether the community health nurses' values identified in this study are held in isolation or shared by others, such as clients and colleagues. This potential for contribution to further research is particularly significant in view of the scarcity of literature avallable regarding the problem of this study.

\section{Practical Significance of the Study}

There are a number of practical implications of this study. First, by contributing to the understanding of community health nurses' personal and professional values, this study could foster the personal and professional growth of community health nurses (Uustal, 1977). Since such growth contributes to more self-confident, better motivated, and action oriented behavior (Simon \& Kirschenbaum, 1972), this study could assist community health nurses to advance community health nursing in a focused and proactive manner. In addition, by enriching the understanding of community health nurses' perceptions about the value of community health nursing, this study may assist nurses to reflect on and make decisions about what it is that they do. This type of reflection could help nurses consider and direct effective and efficient nursing care. 


\section{Definition of Terms}

Community health nurses - registered nurses with a baccalaureate degree in nursing who identify, assess, and respond to the health needs of populations. They work in collaboration with, among others, communities, families, individuals, other professionals, voluntary organizations, self-help groups, informal health care providers, governments and the private sector (Canadian Public Health Association, 1990). The community health nurses in this study will have practised in the field of preventive community health nursing for the previous two years, and will be at the staff level of community health nursing practice in the city of Vancouver. Community health nurses have been so defined for this study in order to access those nurses who have knowledge and expertise in population focused nursing practice (Williams, 1977).

Community health nursing - is an art and a science that synthesizes knowledge from the public health sciences and professional nursing theories. It aims to promote and preserve the health of populations. It is directed to communities, groups, families, and individuals across their lifespan, in a continuous rather than episodic process (Canadian Public Health Association, 1990). Community health nursing, for the purposes of this study, will be aimed at preventive (health promotion, disease prevention, community development) rather than curative (Home Care) services. Also, in this study, the term community health nursing (nurses) will be used synonymously with the term public health nursing (nurses). 
Values - a set of personal beliefs and attitudes about the truth, beauty, or worth of any thought, object, or behavior; values are action oriented and give direction and meaning to one's life (Simon \& Kirschenbaum, 1972).

Values clarification - fosters the making of choices and facilitates decisionmaking. Values clarification involves choosing, prizing, and acting on values; it fosters personal growth and the art of professional practice. (Steele \& Harmon, 1983).

\section{Assumptions}

The following assumptions are inherent in this study:

1. The community health nurses who participate in this study will have experience with and be able to speak to the phenomenon of interest, namely what they value about community health nursing, and

2. The community health nurses who participate will provide frank and honest responses to the questions asked by the interviewer.

\section{Limitation}

The limitation of the study is that the generalizability of the findings will be limited to the population of community health nurses studied due to the study design, the sampling procedure, and the small number of individuals in the sample. However, the phenomenological method is not intended to provide findings that are generalizable to a large population. Rather, it is intended to provide in depth understanding of the perspectives of a small group. The participants of this study are considered to be representatives (or "the experts") of a population of urban community health nurses. Therefore, the findings will 
provide understanding of and be generalizable to the population studied, namely community health nurses in a large urban community.

In summary, this chapter has provided an introduction to the background, conceptualization, and research methodology regarding the problem of this study. Values clarification theory was presented as a framework to examine the values held by community health nurses. The phenomenological method will effectively access these values using in depth interviews and analyses to achieve clarity and understanding. Chapter two will address perspectives offered in selected nursing literature. 


\section{CHAPTER 2: CRITICAL REVIEW OF SELECTED LITERATURE}

\section{Introduction}

This study arose from the author's belief in the value of community health nursing and the important role that community health nurses play in the health care field. Some of the reasons why community health nurses are important players include their ability to practice in diverse settings such as the home and the community, their wide scope of practice in prevention and health promotion, and the respect and trust given to them by the public. However, in spite of these and other valuable aspects of their practice, community health nurses often do not realize goals in shaping health care (Neylan, 1991; Wells, 1991). Andrea Henning, British Columbia's provincial nurse advisor, believes that nurses must be clear and articulate about their nursing values in order to make an impact on and direct health care (Wells, 1991). To facilitate this clear articulation, this author wished to explore further the value of community health nursing from the perspective of other community health nurses. In addition, the author wanted to provide community health nurses with the opportunity to explore and articulate their values, in essence, to give them a voice.

The purpose of this chapter is to provide a perspective of the value of community health nursing as expressed in the literature. To that end, the following literature review presents and discusses the value of community health nursing from various perspectives. The perspectives presented in this review include the community health nurses' perspectives, the value of 
community health nursing within the nursing profession, and the value of community health nursing from the public's perspective.

\section{Community Health Nurses' Perspectives}

A review of the literature revealed a paucity of studies directly related to the perceptions of community health nurses about the value of community health nursing. A recent study (Clarke, Beddome, \& Whyte, 1990), primarily quantitative in nature, asked British Columbian community health nurses to identify and rank ten issues that they believed were critical to directing the preferred future of community health nursing in British Columbla. In order for these nurses to rank the top ten issues from the list of thirty-seven issues options, the nurses needed to determine their valuing of each option. The issues ranked as the top five were increased allocation of resources for prevention, community health nurse involvement in health care planning, client responsibility for self-care, integration of community health services with other health care services and centres, and the need to explicitly and clearly define the community nurse role. These areas could be described as representative of some of the values held by this community health nurse population. The study did not directly ask community health nurses about their perceptions of the value of community health nursing. This study recommended that further research be initiated to identify the knowledge, attitudes, and practices required of community health nurses, today and in the future.

Another study that addressed the perceptions of community health nurses was done by Patricia De Silva (1988) as part of her doctoral studies. De Silva investigated the meaning rather than the value of community health 
nursing. The relationship between meaning and value is illustrated by the following example. The definitional meaning of community health nursing (CPHA, 1990) will be interpreted by each nurse according to the nurse's own value system. One community health nurse may primarily value the art of community health nursing, another nurse may primarily value the science of community health nursing, and their practices will reflect these value interpretations of the definitional meaning. Therefore, De Silva's study provides some illumination for the present study.

De Silva (1988) found that the meaning of public health nursing derived from the participants in her study centered upon the nurse-client relationship and the potentials and limitations of that relationship. The participants in De Silva's study (1988) emphasized the importance of gaining the trust of clients, the need for a sympathetic understanding of clients' perspectives and struggles, and of not being seen as part of the police force. Therefore, the community health nurses in De Silva's study appeared to value the client's perspective which was accessed in an open and trusting nurse-client relationship. However, community health nursing values were not specifically investigated or reported in this study. In addition, this study was performed in the United States, where the practice of community health nursing and the health care system are somewhat different from the Canadian situation.

Two Canadian community health nurses (Rankin \& Leversage, 1991) discussed the need for a definition of community health nursing that is not based solely on the roles of community health nurses. To that end, they proposed seven defining characteristics of community health nursing: (a) a 
focus on the unseparated mass, (b) equal opportunity for health, (c) service from a health perspective, (d) service independent from request, (e) a holistic approach, (f) the knowledge that people are in inseparable interaction with their environment, and (g) a joint assumption of responsibility. Underlying these defining characteristics are values to which community health nurses may ascribe. However, these values are not directly addressed by the authors of this article.

This review of the literature did not reveal any other research that canvassed community health nurses for their perceptions or for their values in relation to community health nursing.

Community Health Nursing Roles and Activities

Values form the basis of actions (Steele \& Harmon, 1983). Nursing values express broad ideals of nursing and establish correct directions for nursing (CNA, 1991). Therefore, some of the value of community health nursing can be described in terms of roles and activities. The Canadian Public Health Association (1990) states that community health nurses have two primary roles, namely health promotion and illness and injury prevention. Activities that community health nurses may use to enact these roles include care/service provider, educator, consultant, community developer, facilitator (leader, enabler, advocate), communicator, resource manager, planner, coordinator, team member/collaborator, researcher/evaluator, social marketer, and policy formulator (CPHA, 1990). Numerous authors (Chavigny \& Kroske, 1983; Dye-White, 1984; Kenyon et al., 1990) have noted the role confusion and various disparate activities that presently exist in community health nursing. 
For example, the roles and activities adopted by community health nurses may vary according to the needs of individuals and populations, the community health nurses' knowledge of, valuing of, and ability to enact community health nursing concepts and activities, and the nature of the multidisciplinary expertise that is available.

Various factors may be contributing to this role confusion. Some of these factors include a decreasing emphasis on adequate and clear community health nursing education within nursing curricula such that new practitioners are not clear about the theory and practice of community health nursing, and the continuing lack of a clear definition of the community health nurse's role (Chavigny \& Kroske, 1983; Dye-White, 1984; Kenyon et al., 1990). These two factors may play interdependent roles with regards to community health nursing role confusion. If community health nurses are not clear about the theory and practice of community health nursing as a result of their nursing education, these nurses will have difficulty identifying and articulating a clear definition of the role of the community health nurse. Conversely, the lack of a clear definition of community health nursing has implications for the effective education of nursing students, the future community health nursing practitioners.

A clear definition of community health nursing is particularly vital in these times of economic restraint. Community health nursing services are often the first services to be discontinued when fiscal cutbacks become necessary (Chavigny \& Kroske, 1983). A clear definition, which identifies and articulates the collective practice of community health nursing, could help to illuminate 
the value of this field of nursing (Chavigny \& Kroske, 1983). The value of community health nursing services and programs could also be more easily and effectively demonstrated through nursing research using a clear definition of community health nursing. The value of community health nursing services and programs must be clearly demonstrated in order that they can be maintained and developed to meet present and future health care needs. A clear definition of community health nursing could facilitate and advance this field of nursing.

Inadequate community health nursing education and lack of a clear definition of the community health nursing role serve to weaken the role, and support replacement of the role with other non-nursing disciplines. Chavigny and Kroske (1983) suggest that because of these factors community health nursing may be lost as a separate nursing entity. Community health nurses must identify and articulate the values that form the basis for their roles and activities in order that they can control and direct their practice (Chavigny \& Kroske, 1983). However, no studies were found that directly addressed community health nurses' perceptions of the value of their roles and activities. Community Health Nursing and the Nursing Profession Community health nurses are members of the larger body of registered nurses and are therefore obliged to meet the requirements of that professional body. In addition to the requirements of the nursing profession, community health nurses are required to demonstrate knowledge and skills specific to their nursing specialty, public health. Some of these requirements include knowledge of and competency in family and community assessment, case 
management, health systems management, epidemiology, concepts and practices of health promotion and disease prevention, and wellness care (CPHA, 1990; Deiman, Jones, \& Davis, 1988; Kenyon et al., 1990). Public health takes an aggregate rather than an individualistic approach to health care which distinguishes community health nursing from other kinds of nursing and makes it a specialty within the profession (Williams, 1977). As a consequence, community health nurses may hold values that distinguish them from other nurses. Indeed, it has been suggested (Salmon, 1989) that value conflicts exist between the nursing profession and public health. Some of these value conflicts include: (a) the primary concern of nursing for individuals and family versus the primary concern of public health for society and the public good, (b) the primary orientation of nursing toward care and cure versus the primary orientation of public health toward the broader goals of health promotion and disease prevention, (c) the emphasis of nursing on professional credibility expressed through technical competency in one to one practice versus the emphasis of public health on more indirect roles and activities in diverse settings, (d) the primary disciplinary relationship for nursing is nursing-focused whereas the primary public health relationship is necessarily interdisciplinary, and (e) the perspective of nursing favors uniformity and consensus whereas the perspective of public health favors a nonstandardized, form-follows-function approach (Salmon, 1989).

Community health nurses then may be caught in a value conflict dilemma because they are both nurses and public health practitioners. They must integrate the values of the nursing profession but they must also adopt 
the values that form the foundation of the public health field. These value conflicts could be important to explore in order to inform the education, practice and research of community health nursing.

The author has been involved in numerous discussions with community health nurses and hospital nurses regarding these differences in value orientations. However, the author did not discover any research that presented the community health nurses' perspectives on these matters.

\section{Trends}

Certain trends within the nursing profession have implications for community health nursing and its value. A survey of the literature relating to these trends is relevant to the problem of this study.

Trends in Nursing Education

Within nursing education, a number of trends are weakening the quantity and quality of community health nursing content within nursing curricula. Some of these trends include: the integration of community health nursing content within other nursing content areas, the lack of recognition of community health nursing as a distinct nursing specialty (Chavigny \& Kroske, 1983; Deiman, Jones, \& Davis, 1988), the undervaluing of community health nursing concepts within nursing curricula (Bell \& Wright, 1990; Salmon, 1989), and the lack of faculty who are well prepared and knowledgeable in community health nursing concepts and practice (Barkauskas, 1982; Bell \& Wright, 1990; Williams, 1981).

As a result, Kenyon et al. (1990) have stated that nursing students are not adequately prepared to enter community health nursing practice. It is 
difficult for nursing students to choose and prize community health nursing values if these values have not been made explicit in theory and practice by credible educators. For example, some conceptual models for nursing used in nursing education curricula incorporate values that are based on an individualistic perspective which is not congruent with the aggregate perspective of public health (Kenyon et al., 1990). Consequently, nursing students may find it difficult to identify and actualize community health nursing values.

Lack of role clarity in the practice arena further complicates the ability of educators to convey clear community health nursing concepts and practices to students. Nurses new to community health may discover that the values presented in the educational setting are not present, not important, or are in conflict with values encountered in community health nursing practice (Kenyon et al., 1990). These nurses may be ill prepared for the specialized roles and activities of community health nursing and therefore may experience burnout and leave community practice and often nursing altogether. As Kenyon et al. (1990) have noted, failure to address adequately the educational and experiential needs of nursing students has left the whole profession vulnerable.

Community health nursing theory is at risk of elimination when this theory is integrated into the curriculum (Chavigny \& Kroske, 1983). As Chavigny and Kroske (1983) have noted, integration of community health nursing has completely subsumed the specialty in many of these curricula. The integrated curriculum is beneficial in its emphasis on holistic care and the importance of intradisciplinary cooperation but, in many integrated curricula, 
public health nursing as a distinct specialty is not taught at all (Chavigny \& Kroske, 1983).

In many integrated and nonintegrated nursing curricula, the values and roles of community health nursing are enacted in a hospital environment or with minimal exposure to the community health nursing environment (Kenyon et al., 1990). This type of exposure is not adequate or appropriate for the transmission of community health nursing values and roles and further serves to undermine the importance of the community health nursing specialty (Kenyon et al., 1990). If students are not given sufficient opportunity to explore, choose, and develop commitment to community health nursing values through appropriate community health experiences, these students may not choose, prize, or act upon these values after their nursing education is completed. As a consequence, the quantity and quality of community health nursing practice are jeopardized.

Community health nursing education is important for experienced nurses as well (Kenyon et al., 1990). Nurses who come to community health nursing with acute care and other nursing experience cannot be expected to have gained the required value orientations and competencies necessary for community health nursing. In addition, the choosing, prizing, and enactment of community health nursing values change with the changing values of nursing, public health, and society (Salmon, 1989). The establishment and maintenance of strong staff development programs within community health nursing agencies could help sensitize community health nurses to these changing values. These staff development programs also have the potential to 
strengthen and to prevent loss of commitment to community health nursing values (Kenyon et al., 1990). As Kenyon et al. (1990) state, "Education must address the reality that community health nursing is an advanced area of practice, and service providers must recognize and accept their increased responsibility to help prepare nurses to work in this fleld" (p. 38).

Trends in Nursing Practice

Trends in and affecting nursing practice emphasize the need to define the goals and responsibilities of community health nurses. Community health nurses could then set priorities among those activities that reflect their special skills. In short, the need exists to define the role and function of community health nursing (Chavigny \& Kroske, 1983; Dye-White, 1984; Elfert \& Anderson, 1987; Rankin \& Leversage, 1991; Williams, 1977). Some of the trends that affect community health nursing practice include: fiscal constraints and priorities, early hospital discharge, an increasing elderly population, and an erosion of the community health nurse role by other health care professionals, such as the family advancement worker and physicians.

These trends may affect community health nursing in various ways. Fiscal constraints, for example, can result in decreasing or eliminating community health programs and personnel, and maintaining acute care funding priority (Chavigny \& Kroske, 1983). Early hospital discharges and an increasing elderly population may require community health nurses to develop more skills in secondary prevention and health maintenance, rather than in health promotion and disease prevention (Laffrey, Renwanz-Boyle, Slagle, Guthmiller, \& Carter, 1990). The erosion of the community health nurse role 
by other health professionals is occurring in many areas; examples of this erosion can be found in the roles of the health educator, social worker, and physician (Chavigny \& Kroske, 1983). Aspects of these roles demonstrate a replacement or an overlapping of community health nursing roles and responsibilities and serve to undermine or obscure the value of community health nursing.

Chavigny and Kroske (1983) discussed three factors that may have contributed to this situation. First, they suggested that community health nursing has been too open to multidisciplinary cooperation and the sharing of roles and responsibilities. This openness has allowed other disciplines to encroach on what once were community health nursing responsibilities. Second, they suggested that the trend toward integrating community health education into the general nursing curriculum has resulted in practitioners who are not certain of their roles, responsibilities, and expertise. These authors believe that the integration of community health nursing education has contributed to the elimination or liquidation of the specialty. The third contributing factor to role erosion is that of role confusion. Community health nurses may be unclear about their roles, responsibilities, and skills and therefore may have difficulty in asserting and claiming their areas of expertise (Chavigny \& Kroske, 1983).

All of these factors and many others may contribute to a lack of clarity and commitment about the value of community health nursing on the part of community health nurses. Since values form the basis for actions, explication 
of community health nursing values should assist community health nurses to develop a clear conception of and commitment to their roles and activities. Trends in Nursing Administration

Trends in community health nursing administration revolve around fiscal constraint and practice issues (Ervin, 1982). Community health nursing administrators must involve community health nurses in determining the nature and the scope of services provided (Hernandez, Kaluzny, Parker, Chae, \& Brewington, 1988; Mason \& Talbott, 1985). Since community health nurses provide services directly, they may hold values about the appropriateness and effectiveness of these services. In order to maintain or change these services, administrators should consult with community health nurses to determine the values they hold about the services and possible courses of action.

Administrators must also stress the value of nursing functions to the professional staff and the community at large (Archer, 1983; Jenny, 1990; Josten, 1989). This may prove problematic in that the value of community health nursing has not been clearly identified and articulated in terms of unique roles and activities, and in terms of research that clearly proves the worth of community health nursing services. Pender (1987a) suggests that prevention and health promotion programs need to be assessed in terms of cost-benefit and cost-effectiveness analyses in order to successfully compete with treatment-oriented programs for health care dollars. He encourages nurses to be aware of the basic principles and concepts underlying each of these cost study methods, and he believes that nurses should promote and become involved in such activities. Community health nurse administrators 
could play a pivotal role in promoting and participating in these cost study analyses.

Administrators must also be aware of and address aspects of nurses' job satisfaction if they are to attract and retain effective community health nursing personnel (Lucas, McCreight, Watkins, \& Long, 1988; Rankin \& Leversage, 1991; Riordan, 1991). Job satisfaction in nursing is closely allied with feeling valued and important within the health care system. Community health nurses are more satisfied with their work if they perceive it to be important and believe that others value it as well (Riordan, 1991). These nurses are more likely to be committed and stay in community health nursing. If new practitioners determine that community health nurses feel satisfied in their work and feel valued, they are likely to be attracted to working in this field of nursing. Administrators then have a responsibility to identify the values that community health nurses hold, to assess the fit between these values and community health nursing goals, and to demonstrate appreciation of their nursing staff in order to attract and maintain effective and committed community health nursing practitioners.

In addition, administrators should develop personal attitudes that facilitate recognition of the value of community health nursing staff (Riordan, 1991). These attitudes on the part of administrators further promote job satisfaction and a sense of worth among staff (Riordan, 1991). Administrators should also facilitate assertiveness and risk taking in their staff so that community health nurses can seize vital moments in their practices (Riordan, 
1991). Such values and actions on the part of administrators may assist community health nursing to become all it can be.

Trends in Nursing Research

Goeppinger (1988) and Oda (1988) note the pressing need for research in community health nursing. Goeppinger (1988) examines five issues that make community health nursing research particularly problematic: (a) confusion about the domain of community health nursing, (b) inadequate definition of key concepts such as community, (c) inappropriate competition among research methods, (d) unpredictable collegial and financial support, and (e) inattention to the dissemination of research findings in practice environments. These research difficulties in themselves militate against obtaining adequate financial support for research, which is essential to promoting effective community health nursing education and practice.

Oda and Boyd (1987) also note that prevention oriented community health nursing is difficult to research and measure due to its qualitative nature and location in bureaucratic systems. They suggest six steps that are useful for the documentation and analysis of the effects and cost of community health nursing field services. These six steps are as follows: (1) focus and delimit the service or intervention to be examined within a specific program, (2) determine specifically the outcome to be measured, (3) select the service or mode(s) of intervention, (4) brainstorm with the participating staff as to the actual activities that constitute the service selected as they perceive it, (5) decide upon a time period for the application of the intervention, and (6) select comparison group subjects. The use of these six steps by community health nurse 
practitioners, administrators, and researchers could facilitate the research process in the field of community health nursing.

Nursing research can provide data about the value of community health nursing in a variety of areas. Research can confirm and demonstrate that significant differences have been and can be made by community health nurses and community health nursing (Sullivan, 1984). By affirming the value of community health nursing, research could play an important role in persuading those in power positions to influence the direction and amount of resources allocated to community health nursing and prevention services (Sullivan, 1984). In these times of economic restraint and in the presence of increased competition for a share of the health care dollar, and when community health nursing services are often the first services to be cut back, nursing research has an important role to play in promoting the recognition and funding of valuable community health nursing services.

Research and the values that community health nurses hold may be in a reciprocal relationship. This relationship may be reciprocal in that these values can help to direct research to what community health nurses consider as important in their work, and conversely, data uncovered or clarified by research can affect the values that community health nurses hold about their work. Consequently, the relationship between research and community health nurses' values may help to define the nature of community health nursing practice, assist in community health nursing educational objectives, and increase the effectiveness of clinical practice (Chavigny \& Kroske, 1983). In conclusion, research and the values of community health nurses are mutually useful and 
vital to the explication and enactment of effective community health nursing practice.

\section{Community Health Nursing and the Canadian Public}

Minimal literature was found that addressed the value of community health nursing held by the Canadian public. During a recent strike by community health nurses in British Columbia, the public responded with confusion and apathy about the withdrawal of services (Rankin \& Leversage, 1991). However, a Canadian study by Elfert and Anderson (1987) of parents of pediatric clients found that the care provided by community health nurses was clearly valued by these parents. American studies (Barkauskas, 1983; Gulino \& LaMonica, 1986) register the effectiveness of community health nursing roles and services that are similar to those in Canada. However, these studies were quantitative in nature and used written information rather than direct reports from community health nurses or their clients regarding the value of these services. Elfert and Anderson (1987) emphasize, "Nurses must learn to step back from their goal-oriented activities and daily duties to try to see themselves and indeed all of nursing as their patients do" (p. 17). However, no literature was found that presented the community health nurses' perspective of their clients' value of community health nursing.

The value of community health nursing needs to be articulated and promoted so that the public may come to know, value, and utilize community health nursing services. Kalisch and Kalisch (1984) have noted that the press image of community health nurses in the United States is in a state of decline. Although community health nursing articles comprised the largest share of all 
clinical nursing articles in their study, these articles were less visible in newspapers, distributed unevenly among the various states, and written so as to communicate low-quality information. Such information does not promote the valuing of community health nursing by the public, or by community health nurses themselves.

This undervaluing has implications for the maintenance and advancement of the community health nursing field. If the value of community health nursing is not adequately portrayed in the press, the public may not be aware of or utilize community health nursing services. As a result the maintenance and development of the community health nursing specialty could be in jeopardy. Kalisch and Kalisch (1984) noted that the informational quality of press news about community health nurses is a critical factor in gaining the required public support for the scarce resources needed to advance community health nursing practice. They recommended that community health nurses embark on a concerted campaign to improve the quality of information carried in newspapers about their clinical specialty and its value.

In summary, literature has been revlewed regarding the value of community health nursing from a variety of perspectives. The perspectives reviewed include those of community health nurses, the nursing profession, and clients. This review reveals the centrality of community health nurses' perceptions of the value of community health nursing to the continuation and advancement of this field of nursing. Furthermore, the review has revealed a lack of articulation of the value of community health nursing and some of the factors which may be contributing to this lack. Nevertheless, the literature is 
mostly suggestive and impressionistic with respect to a full articulation of the present crisis in community health nursing. The next chapter will describe the method used to access and determine study participants' perspectives regarding the value of community health nursing. 


\section{CHAPTER 3: METHODOLOGY}

The qualitative method of phenomenology was used to address the research question of this study. This chapter describes how this method was interpreted and utilized in the selection of the study sample, data collection and data analysis, and in addressing issues of reliability and validity.

The Phenomenological Method

Phenomenology is a research method that guides thinking from theoretical abstraction to the reality of lived experience (Field \& Morse, 1985). The aim of the phenomenological research method is to describe lived experience through attention to the perceived world of the participants (Oiler, 1986). In this study, the aim was to describe the value of community health nursing from the perceptions of experienced community health nurses. Lived experience is acknowledged as subjective reality constituted in a concrete physical and social world and that forms a complex whole (Munhall \& Oiler, 1986). The lived experience of the value of community health nursing of each of the community health nurses who participated in this study is constituted in the physical and social worlds of each of their workplaces, and within the context of their day to day work. Phenomenology enables the researcher to acquire meaning and understanding from the perspective of the study participants (Colaizzi, 1978). The researcher who uses this method strives to approach the phenomenon with no preconceived expectations or categories and to understand the subjective meanings that the phenomenon had for the participants (Omery, 1983). The 
description of lived experience is accomplished by returning to the phenomenon itself, and investigating it in a meaningful way by going to the people experiencing the phenomenon where they are in the world (Colaizzl, 1978). In this study, the researcher investigated the value of community health nursing by returning to community health nurses at their workplaces so as to understand the value of community health nursing in a meaningful way. Phenomenology attempts to lift the layers of experience so as to achieve clear understanding of and insight into human experience (Oiler, 1986). This understanding and insight is achieved through repeated, in-depth interviews with participants. In this study, each participant was interviewed twice, and three participants were interviewed three times in an effort to achieve insight into the value of community health nursing from the perspective of participants. This method is metaphorically akin to peeling away the outside layers of an onion so as to reach the core essence of that onion. Phenomenology, then, attempts to achieve meaning and understanding of reality from the perceptions of the individuals who are living that reality.

\section{Sample Selection, Recruitment, and Size}

Colaizzi (1978) asserts that research subjects in a phenomenological study must meet the criteria of experience with the investigated topic and be articulate in communicating about that experience. In this study, participants were selected who had a minimum of two years of community health nursing experience and who could communicate their perceptions about the value of community health nursing as a result of that experience. Because the phenomenological method involves extensive, in-depth interviews to acquire 
meaning, understanding, and description from data that are comprehensive, relevant, and detailed, the sample size is limited (Morse, 1986). Because of the small sample size and the time and effort involved in data collection and analysis, the researcher must strive to obtain the most insightful data possible from participants who are knowledgeable about and receptive to the topic under investigation. In this study, comprehensive data that facilitated understanding of the value of community health nursing was achieved with a sample size of eleven participants.

Non-probability sampling maximizes opportunities to meet the criteria for data collection and was used to select the participants for this study. The assumption underlying non-probability sampling is that all individuals in a setting are not equally informed about the knowledge sought by the researcher as a result of their roles, age, past experiences, ability to recall, observational skills, interest in the research topic, and other such factors (Morse, 1986). Furthermore, some individuals are more receptive to being interviewed and are more likely to divulge information. Non-probability sampling is appropriate for a phenomenological study since the intent of the research is to access data from participants who are knowledgeable about and can speak to the phenomenon of interest (Morse, 1986). In this study, the researcher set inclusion and exclusion criteria to ensure that selected participants would have characteristics and knowledge that would enhance understanding of the value of community health nursing. All community health nurses who met these criterla were given the opportunity to participate. 
Non-probability sampling incorporates aspects of theoretical and purposive sampling techniques (Morse, 1986). In theoretical sampling, subjects are selected because they can illuminate the phenomenon. In this study, community health nurses with a minimum of two years of community health experience were selected as participants because of their ability to illuminate their perceptions of the value of community health nursing as a result of their direct experience in that field of nursing. The researcher expected these nurses to be able to elaborate upon the value of community health nursing in general holistic terms, for example in relationship to other fields of nursing and to the larger society. In addition, the researcher expected that the nurses would be able to articulate their own particular values in relation to community health nursing, for example their values underlying their particular practices.

In purposive sampling, the selection of the participants is based on criteria set out by the researcher based on what needs to be known or verified (Morse, 1986). For this study, participants were selected according to the inclusion and exclusion criteria specified below.

The inclusion criteria were that the participants must be:

1. registered nurses who hold a baccalaureate degree in nursing,

2. community health nurses at the staff nurse level in a major urban health department and who have been working full-time for the past two years in preventive community health nursing, and

3. able and willing to honestly and openly speak to the experience identified in the research question. 
The exclusion criterion was that the study participants must not be primarily involved in home care or other community health nursing practice that is not primarily prevention focused. These inclusion and exclusion criteria were specified so that the research question would be addressed comprehensively and clearly by a particular group of nurses who had relatively similar education and preventive health nursing experiences. Using these participant criteria, the researcher attempted to achieve an understanding of these particular nurses' perceived value of community health nursing.

After approval of the study was obtained from the University of British Columbia Behavioral Sciences Screening Committee and the Health Department, the researcher initiated the recruitment of community health nurse participants. Copies of the Information Letter to Community Health Nurses (Appendix A) were distributed to those contacts stipulated by the Health Department Ethical Review Committee. These contacts, who were the preventive health nursing supervisors or managers for each of the four health units in this health department, then distributed the letters to eligible community health nurses. In addition, some of the supervisors offered to post the Information Letter in the communication books at their health units to further inform community health nurses about the study. Opportunities for informal recruitment by the researcher occurred in two of the health units as a consequence of the employment of the researcher in these units. These opportunities consisted of ensuring that the Information Letter was posted in areas that were visible to potential participants, and in addressing their questions and interests regarding the research using nondirective but informative responses. The researcher was careful to provide 
information that would not bias or coerce these potential study participants. Those community health nurses who were interested in participating in the study contacted the researcher.

The researcher then approached in person or by telephone those community health nurses who were interested in participating and provided them with further information about the study if requested. Few participants requested further information, but of those who did, the type of information they requested related to such research practicalities as their time commitment to the research, place of the interviews, and whether or not they should be preparing prior to the interviews by reading nursing information or in any other manner. The researcher provided information that addressed these concerns and clarified the expectations of study participants. In addition, during this initial contact with each participant, a suitable place and time for the first interview were established.

Sample size using the phenomenological method is determined by the data that emerges during the research. When data saturation occurs, the researcher gains understanding of the situation or setting, obtains coherence, and does not collect any new information, through new research subjects (Morse, 1986). In this study, data saturation began to occur during the data collection and analyses of the interviews of the seventh and eighth participants. At this point in the data collection process, the researcher began to understand the value of community health nursing in terms of themes that were common to these eight participants' interviews, such as the value of their roles and activities. Also, the researcher began to obtain coherence, a dense and 
consolidated understanding of the value of community health nursing, from the rich descriptions provided by these participants. Finally, the researcher began to identify data saturation.

Data saturation, and therefore sample size, are also indicated by the nature of the data emerging from the interviews. The data generated by the individuals in the sample should promote a rich understanding and provide an accurate description of the phenomenon under study (Omery, 1983). The researcher continued to collect data from two more participants who were from health units not yet represented in the study. The researcher wanted to include community health nurse participants from all four of the health units so as to obtain a rich and accurate understanding of the value of community health nursing from a variety of perspectives.

The perspective of each participant regarding the value of community health nursing may be influenced by the policies, populations served, the physical arrangement and many other factors that are unique or characteristic of the health unit in which the participant works. For example, three of the health units are involved in the implementation of the Orem Self-Care Model (1985), one health unit has not adopted this model. The use or non-use of a particular nursing model and the values that a model embraces may influence the value that participants place on community health nursing.

The ninth and tenth participants in this study were from a health unit that has not adopted the Orem Model (1980). In addition, this health unit is presently undergoing a reorganization from a traditional one to one type of community health nursing practice to a socioenvironmental, community 
development (RNABC, 1992a) type of practice. This health unit has organized community health nursing practice to focus on three specific age groups with the expectation that community health nurses will be involved in more group and community activities rather than one to one client interactions.

Because of these influences and other variations in health units, the researcher included participants from all four health units. Representation from all four health units helped to ensure a complete, accurate, and rich understanding of the value of community health nursing from a variety of participants' perspectives. In addition, by including participants from all four health units, the researcher maximized opportunities to obtain insightful data, and was better able to further explore, confirm, or refute emerging theory. Since the researcher's purpose in a phenomenological study is to demonstrate the typicality of a phenomenon (Field \& Morse, 1985), the researcher included participants from all four health units. Their perspectives could identify common themes of community health nursing value held beyond the uniquenesses of their work situations.

The eleventh participant was included in the study because of her interest and persistent efforts to be a part of this research. This participant was on vacation when the study was initiated and had difficulty in accessing the researcher to volunteer to participate after returning from holidays. In deference to this participant's enthusiasm, interest, and persistence, the researcher included her in the study.

Community health nurses from all four health units expressed much interest in participating in this study. However, the researcher could not include 
all of those nurses who wanted to participate for a variety of reasons. In addition to practical considerations in relation to the volume of data, some of the community health nurses did not meet one or more of the inclusion criteria, particularly the criterion of two years of recent full-time preventive community health nursing experience. This criterion was set by the researcher to ensure that participants would have adequate experience in and knowledge about community health nursing practice so that they could speak about the value of community health nursing based on this experience and knowledge. Second, when data saturation began during the seventh and eighth interviews, the researcher began to focus data collection from participants in a health unit not yet represented in the study so as to obtain as comprehensive data as possible. This decision necessitated selection of participants from the health unit not yet represented and necessarily excluded selection of participants from health units already represented.

\section{Characteristics of the Participants}

All of the eleven community health nurse participants were at the staff nurse level, and were directly involved in preventive community health nursing in one of the four health units in a large urban health department. They all held baccalaureate degrees in nursing. The majority of the nurses obtained their degrees after initial registration as a nurse and in various provinces in Canada. The eleven participants had diverse nursing experiences including hospital employment and community health employment in other settings and countries such as in England, Africa, and in rural and northern Canada. Although all of the nurses had the minimum study inclusion requirement of two years recent 
community health nursing experience, many had been working in community health for much longer, two nurses for fifteen and twenty years respectively. Six of the participants, the majority of the sample, had three to six years of community health nursing experience. The age range of the participants varied from the mid-thirties to late fifties, with the majority of the nurses being forty to fifty.

\section{Ethical Considerations}

Prior to and during data collection, measures were implemented to protect the ethical rights of the community health nurse participants. A written explanation of the nature and purpose of the study, the risks and benefits of participation, the data generation method, and the retention, dissemination, and destruction of data was offered to each participant (Appendix A). Each participant gave informed and written consent prior to the initiation of the study (Appendix B). This consent included permission for taping of the interviews and offered assurance to participants that they had the right to stop the taping or have any section of the tape erased at any point in the interviews. Assurance of privacy, confidentiality, and anonymity was given to each participant. Also, the community health nurses were assured that they could refuse to participate without jeopardizing their employment. In addition, each participant was given a copy of the Information Letter to Community Health Nurses and the Consent to Participate form.

\section{Data Collection}

A necessary requirement of the phenomenological method is that the researcher and the participant investigate and explore the phenomenon together 
as they attempt to reach clear understanding and insight (Colaizzi, 1978). However, the researcher must not influence or bias the experience of the participant with the researcher's preconceived ideas or understandings (Oiler, 1986). In phenomenology, "bracketing" (Oiler, 1986) is used to suspend the researcher's assumptions regarding the research question so as to fully understand the perceptions of the participants, and so as to not impose the researcher's assumptions on participants. For example, the researcher must suspend personal perceptions about a particular value of community health nursing, such as the value of preventive health nursing as compared to the value of acute care nursing, by analyzing and recording these personal perceptions in a log or journal. Bracketing assists the researcher in identifying perceptions that are separate from the perceptions of the participants. Bracketing, therefore, facilitates the scientific enterprise of the research because the perceptions described represent those of the participants, and not a mirror image of the preconceptions, values, and beliefs of the researcher (Hutchinson, 1986).

The researcher bracketed prior to and during data collection and analysis by recording in a journal. The researcher bracketed prior to beginning the first, second, and third sets of interviews and prior to and after interviewing various participants. Bracketing done prior to and at the completion of the first, second, and third sets of interviews helped the researcher clarify what had occurred during the research process and plan for future interviews and analysis. Bracketing during data collection and analysis assisted the researcher to address perceptions that were in conflict with the researcher's perceptions as discussed by participants prior to, during, and after interviews. An example would be when 
a participant stated that she did not believe that the baccalaureate degree was necessary for all registered nurses. The researcher also bracketed when value congruence between the participant and the researcher occurred, for example when a participant stated that she believed that the value of community health nursing was not readily visible to clients and to other fields of nursing.

The researcher also recorded personal analyses of and responses to perceptions which the researcher had not previously considered or had not considered as significant or relevant, for example expressions by more than one participant about the value of being listened to and the increased need for this in the workplace. (The researcher had assumed that this readily occurred in all health units based on the researcher's past experience in community health nursing). Bracketing therefore assisted the researcher to address her own personal perceptions, beliefs, assumptions, and values so that the perceptions of the participants would not be influenced.

The researcher worked part-time as a community health nurse in one of the health units during the study. As a consequence, the researcher believed it was important to keep personal expressions about the value of community health nursing to a minimum with nursing colleagues in the workplace. These personal feelings and responses to colleagues' values and beliefs were also bracketed in the journal. For example, during meetings with community health nursing colleagues to discuss roles and activities and their purposes and value, the researcher restricted her personal perceptions to avoid influencing potential participants. The researcher later bracketed personal perceptions and reactions that resulted from these meetings in the journal. This technique helped the 
researcher reflect upon personal perceptions acquired as a result of direct contact with community health nurses without unduly influencing the research.

Bracketing also assisted the researcher to analyze and clarify what the researcher's values were and why the researcher held these values. Therefore, the researcher became more self-aware, and this self-awareness helped the researcher to be sensitive to participants' perspectives. For example, one participant remarked that the study interview caused her to think about nursing in a philosophical manner which she had not done before, and the researcher bracketed in the journal a personal response to this comment. The researcher recorded how thinking about these issues in a philosophical manner seemed second nature to the researcher, possibly due to the centrality of the issues to the researcher's personal value system, and to her reflection upon these issues. Because the researcher has ten years experience as a community health nurse and has studied extensively in this field of nursing, bracketing proved to be essential in keeping the researcher's perceptions about the value of community health nursing separate from the participants' perceptions.

During data collection the researcher was aware of the need to establish a trusting dialogical relationship with each participant. This type of relationship encourages full participation by the study participants and the researcher as they explore together deeply personal presuppositions (Colaizzi, 1978; Field \& Morse, 1985). For example, as participants came to know the researcher as a receptive and nonjudgemental person who was genuinely interested in their perceptions, they became more comfortable and revealed data about their values that was of an intimate nature, such as one participant's negative experience 
during her baccalaureate nursing education program and how this impacted upon her valuing of the baccalaureate degree for community health nurses. The researcher noticed that rapport and trust developed between the researcher and the participant as the first interviews progressed, and was more evident in second and third interviews. During these latter interviews, the researcher felt comfortable in asking participants to probe deeper into their values and the bases for these values, and the participants seemed relaxed in responding to these probes. For example, during a second intervlew in response to the researcher's report that some participants had noted low morale within their health units, a participant responded by replying that the reasons for this could be attributed to a feeling of not being listened to by nursing administration, as well as due to the personalities and personal life situations of the community health nurses themselves. The data collection process required sensitivity on the part of the researcher to the disclosure and exploration of personal and professional issues.

Inasmuch as the researcher was asking participants to divulge their value orientations, the researcher also needed to be receptive to participant questions regarding the researcher's value orientations or the research process and findings. For example, as participants became comfortable with the researcher and often prior to the second interviews, they would occasionally make comments similar to the following, "So, how is the research going? What are you finding out? Anything new?" or " Who is in your study? Is so and so in your study?" or "How are things going at the health unit where you're working?" The researcher was careful to respond in a genuine but neutral manner so as to not 
bias the participant's perceptions and so as to maintain the confidentiality of the participants. By virtue of this response, and in acknowledging the interest of the participants, the researcher hoped to foster a trusting, open and collegial relationship with participants.

In addition, in order to foster a trusting dialogue that would facilitate value exploration, the researcher also incorporated into the interviews and other researcher-participant contacts the following assumptions and approaches of Colaizzi's dialogic interview (1978):

1. The researcher realized that the participant was more than a source of data - she was exquisitely a person.

2. The researcher made contact with the verbalized experiences of the participant only when listening with her total being and entirety of personality.

3. The dialogue was between two persons of equal level without social or professional division.

The researcher addressed these assumptions and approaches in a number of ways. Interviews were scheduled at times and locations convenient to each nurse. Prior to each interview the researcher spent a few minutes with the participant in informal conversation, frequently over a cup of coffee. During the interviews the researcher assumed a relaxed posture and was intently attuned to the verbal and nonverbal communications of the participants. If a participant was unable or unwilling to address various values during the interviews, the researcher respected that, and pursued investigation of the value only to the degree to which the participant was comfortable. For example, some participants stated that they could not address the value of community health nursing 
education for nursing students since they had graduated from their nursing programs a number of years ago, and were not familiar with present nursing education programs. These participants did not feel qualified to comment on this value. The researcher respected these perceptions, and only addressed value perceptions that these participants felt able to discuss.

Data was collected in private settings at the health units for all but one of the interviews; one of the community health nurses was on leave and the second interview was carried out at her home. Each of the eleven community health nurse participants was interviewed twice over a period of four months. Three participants were interviewed a third time.

The first interviews were guided by a semi-structured format using openended trigger questions (Appendix C) as well as by the feelings, thoughts, and perceptions of each participant. The trigger questions served to initiate discussion and most participants readily volunteered their perceptions regarding the trigger questions and other value considerations that they believed to be important. However, if a participant had not previously considered some of the values raised by the trigger questions or by other value related questions posed by the researcher, then the researcher encouraged the participant to reflect and elaborate upon these new considerations. For example, some participants had not closely considered the value of research within the community health nursing role, but when given encouragement and time by the researcher to consider this aspect, most participants were able to provide perceptions about the value of research to community health nursing. 
Encouragement to consider and discuss personal value perceptions was only pursued to the degree that the participant felt able and willing to participate. For example, one participant described negative perceptions about nursing administration based on her personal unpleasant experiences with a particular nursing administrator. The participant was uncomfortable and reluctant to address certain details of this relationship, and the researcher respected the participant's unwillingness to pursue this topic. The discussion moved on to other value perceptions that the participant felt more able and willing to address.

The researcher attempted to access meaning in these first interviews by asking participants to elaborate on the reasons for their perceptions, the "why" of the values they held. The purpose of these first interviews was to gain a preliminary description of each participant's values in relation to community health nursing. In addition, as the number of first interviews increased, and collective meanings and themes began to emerge from the data, the researcher began to focus the subsequent first interviews to achieve deeper understanding of these meanings and themes.

For example, as the theme of the value of community health nursing visibility began to emerge from some of the initial first interviews, the researcher explored with other participants in their first interviews the presence of this value and its in-depth meaning to these participants. During a first interview with one of the last of the participants, the importance of visibility was revealed in terms of government funding and support, " Absolutely [the government undervalues us]. Oh, what do you do? It's very invisible, it's very invisible. You 
get a lot more votes for bullding a 20 storey building on 12th and Oak..." Another participant revealed in the first interview that visibility was important for awareness of and effective use of community health nursing services, " [Community health nurses] find that very discouraging that the doctors don't really understand our role and they don't see it as being an important role at all...I think a lot of doctors...haven't realized what we are trying to do. Or how we could help them in what they are trying to do." This perception also speaks to the value of visibility in terms of role clarity and collaboration with others. Therefore, as the first interviews proceeded, the quantity and quality of the data increased so as to provide a comprehensive and rich understanding of the value of community health nursing.

The second interviews were scheduled after the researcher had analyzed each of the first interviews, approximately six to elght weeks after each of the first interviews. These second interviews were primarily for clarification, elaboration of the descriptions, and validation of the dialogue. For example, one participant stated in the first interview that the support of her colleagues was very important to her. In the second interview with this participant, the researcher asked her to clarify what she meant by support and to elaborate upon why this support was personally important. In the second interview with another participant, the researcher indicated her understanding of the participant's perceptions of job satisfaction which had been derived from the analysis of the first interview. The researcher then asked the participant to validate the researcher's understanding of the participant's perceptions. 
Participants were also given opportunities in these second interviews to add any other relevant perceptions about their values that had developed since the first interview. One of the participants stated that discussion in the first interview had caused her to consider more deeply her participation in nursing research. As a result, she initiated discussion and presented her perceptions on nursing research in the second interview. Other participants remarked on how they were more sensitive to their values about community health nursing following their first interviews, and how they had devoted more time and thought to the value of their work as a result of their participation in the study. Some of the participants remarked on certain issues that they had thought about in the time between the first and second interviews. Some of these issues included nursing research, the value of administration to community health nursing, and ways to promote community health nursing to others.

These second interviews included discussion and developed data that were on a deeper and more fundamental level than the data in the first interviews. This deeper level of abstraction ascertained some of the participants' core values and reasons for adherence to these values. The researcher sought to access this deeper understanding and insight by asking participants to elaborate on what their values were, on what bases they were held, and why they were important to each participant. For example, the researcher explored with a participant in the second interview the value of collegial support held by herself as well as by other participants. After addressing this theme at length, the participant concluded by stating that collegial support is important to her for some fundamental reasons, "...I guess maybe I'm human (laughs) and I need that support from other human 
beings. We realize that we are facing similar problems, similar frustrations, and yet we have similar hopes for the future and that enhances the spirit."

The establishment of a trusting relationship with the participants during the first and second interviews, and the interest and attentiveness of the researcher facilitated this deeper level of abstraction. In addition, some participants remarked on the value of exploring, considering, and clarifying their values in a nonjudgemental way. The participants also were highly articulate, thoughtful, and committed to accurate and clear descriptions of their perceptions. These characteristics enhanced the quality of the data that the researcher was able to access in the study. Consequently, the researcher believes that the participants were eager and able to present their true perceptions about the value of community health nursing. By the end of each of the second interviews, the participants and the researcher agreed that the value of community health nursing from the participants' perspective had been articulated.

Third interviews were done as a final validation of the formulated description of the value of community health nursing. This formulated description is a statement of the essential structure of the value of community health nursing from the perspective of the participants of the study, and was produced by integrating the results of the analysis (Colaizzi, 1978). The formulated description must unequivocally reflect the value of community health nursing as perceived and described by the participants. The researcher formulated this description directly from the themes that arose from the analysis of the interview data. A final validation was undertaken by returning to three of 
the participants. Such validation is a means of checking the accuracy of the researcher's interpretation of the data (Streubert, 1991). It is also a test of validity in that those who have experienced the phenomenon, in this study community health nurses, should be able to recognize the phenomenon, the value of community health nursing, from the description developed by the researcher (Colaizzi, 1978).

When the researcher returned to the participants for the third interview, she asked them to read the formulated description and consider whether or not this description validated or reflected their experience and contained the essence of their perceptions (Colaizzi, 1978; Riemen, 1986). In addition, during the third interviews the researcher asked participants if there were aspects of their experience or perceptions that the researcher had omitted.

All three participants stated that the description validated and contained the essence of their perceptions of the value of community health nursing and that the researcher had not omitted any essential aspects of their experience. In fact, one participant was amazed at the degree of accuracy that the description reflected, and asked the researcher how she was able to so completely capture the essence of the value of community health nursing. Because all three participants validated the description and had nothing further to add to it, the researcher did not return to other participants for a third interview.

The first and second interviews varied from thirty-five minutes to an hour and a half with most interviews being approximately an hour in length. The third interviews were shorter, lasting approximately a half hour. Each of the first and second interviews was taped and transcribed verbatim. Special attention was 
given to maintaining the confidentiality of the participants. The third interviews were taped but not transcribed. Two of the nurses requested and were given transcripts of their first interviews prior to analysis. They stated that the transcripts helped them to think about and clarify their values.

Colaizzi (1978) states that phenomenology, by seriously including the trusting dialogical approach, passes beyond research in its limited sense and occasions insight and therapy. Indeed, some of the community health nurses remarked upon how their participation in this study had facilitated their thinking about and clarifying personal and professional values. They felt that an attentive audience enabled them to seriously explore their values in ways that they had not done before.

The researcher too discovered that her values shifted and evolved throughout the course of the data collection and analysis procedures. These changes occurred as a result of the various values presented and discussed in the interviews. Some of these value perspectives were new to the researcher, and some of the participants presented their values in ways that the researcher had not previously considered. For example, some participants valued graduate level education for community health nurses but noted that opportunities for career advancement that utilized this education were not readily available for community health nurses in this major urban center. This was a new perspective to the researcher, a perspective that caused the researcher to evaluate graduate level education and community health nursing practice in a new light. The researcher's change in values was an unexpected development that proved to be a rewarding growth experience for the researcher. 
The researcher felt deeply privileged to be allowed into the most personal parts of the participants' thoughts and feelings. As Uustal (1977) notes, dialogue that pertains to values can be therapeutic and result in personal and professional growth. The phenomenological method fostered such growth on the part of the participants and the researcher.

\section{Data Analysis}

In using the phenomenological method, data analysis occurs concurrently with data collection (Colaizzi, 1978). During each interview, the researcher was actively involved in determining the meaning of the verbal and nonverbal communication of the participant, and in analyzing this meaning for common themes. Points for clarification and exploration were raised by both the researcher and the participants during the interviews in an attempt to reach a mutual and clear understanding of the descriptions of the value of community health nursing. For example, one participant stated, "...being in the community you have to be able to acknowledge that that person is getting along out there. And that you may have something to offer them in order to make their getting along easier, to make their progress more direct towards a goal...what are they doing right? What can they do?" The researcher clarified her understanding of this statement by stating, "By recognizing the strengths and limitations of your clients...Doing with in community health as opposed to doing for." The participant agreed that the researcher understood what she meant and added, "And building on what is there as opposed to just going in and doing everything." This perception was repeated by other participants and emerged as a subtheme from the study data. 
In addition, prior to the second interviews, the researcher developed two lists of issues derived from the analyses of the first interviews that required clarification, elaboration, or validation. These lists included both general and specific issues. The general issues list addressed value perspectives that were important for community health nursing and for community health nurses in general, for example, what is personally rewarding about community health nursing. In addition, the researcher included in the general issues list those concepts that seemed to be emerging as common themes from interviews with other participants, for example, the knowledge, skills, and attitudes that community health nurses in other interviews deemed valuable. In the second interviews, participants were asked to validate whether or not themes from this general issues list were significant to them (if the participant had not yet addressed that particular theme), and why they were significant or why they were not significant. The specific issues list addressed value perspectives that had been discovered during data analysis of the first interview with a participant and that required clarification, elaboration, or possible validation by that particular participant. The specific issues list therefore was unique to each participant. For example, after a first interview the researcher discovered that further clarification as to why the participant felt that collegial support was important to her was needed, and in the second interview this issue was addressed in more depth and detail by the participant when the researcher asked for further clarification. Both of these lists helped to guide the second interviews so as to achieve a clear and comprehensive understanding of the value of community health nursing from the participants' perspectives. 
Each interview was analyzed prior to the subsequent interview with another participant using the method developed by Colaizzi (1978). First, statements regarding the value of community health nursing that were significant were underlined on the transcript in red ink. Next, the meaning of each significant statement was formulated in a column directly to the right of the statement. These meanings were arrived at by reading, rereading, and reflecting upon the significant statements in the original transcriptions to get the meaning of the participant's statements in the original context. Next, in a column to the right of the meaning units column, the researcher recorded themes derived from the formulated meanings. Themes are defined as essences or "unities of meaning intended by different individuals in the same acts or by the same individuals in different acts" (Natanson, 1973, p. 13). A third column in the left margin of the transcript was allocated for points that required clarification or exploration in a subsequent interview. For example, one participant stated, " I value the independence [community health nursing] gives me. I find that very liberating I guess, and a challenge as well. I have to make the decisions that I go with at the time". The researcher extracted these as significant statements and underlined them on the transcript. To the right of the statement the researcher interpreted this statement to mean that the nurse valued independence and control over decision making. From the attributed meaning and the underlying statements it was derived from, the researcher determined that the nurse was speaking about the theme of autonomy. To the left of the statements, the researcher made a note to ask this participant in the second interview to elaborate upon why she found this independence liberating and challenging, so that the researcher could better 
understand the nature of the autonomy experienced and valued by community health nurses. This type of analysis was performed for each of the twenty-two interviews and allowed the researcher to refine the trigger questions to access data that would clearly explicate the value of community health nursing. This analysis also helped the researcher determine data saturation, that is when participants began to address themes that were common to other participants' perceptions.

Analysis of the data as a whole was then done by the researcher and this part of the analysis was also guided by a recognized method (Colaizzi, 1978). A detailed description of the steps of this part of the analysis as used in this study is outlined in the following paragraphs. Each step of the analysis was guided by two concerns: (1) to capture the essential meaning of what the participant's perceptions reveal about the value of community health nursing, and (2) to remain as faithful as possible to each participant's original description.

First, all of the transcripts of the twenty-two interviews were read to obtain a general sense of the essences or commonalities in the participants' descriptions of the value of community health nursing. The researcher paid particular attention to the significant statements, meaning units, and themes that had been noted in previous analyses, as described above. In addition, this comprehensive and intensive re-reading of all of the transcripts contributed to further analysis; the perspectives from all of the interviews were collectively brought to bear on each participant's perspective. Emerging themes and the connections among the themes from various interviews became more obvious after re-reading and reflection. 
Next, the researcher recorded on separate paper all of the themes that emerged from each of the twenty-two interviews. This was done by returning again to each transcript and noting themes that had emerged from previous reading and analysis. Themes that seemed of particular significance to the researcher as a result of repeated in-depth encounters with the data or that were emphasized by participants in terms of repetition or emphatic discussion by one participant or by various participants were recorded. Beside these themes the researcher noted the name of the participant, the interview number, and the page of the transcript to facilitate further reflection on that theme by the researcher. During this recording process, the researcher found it necessary to repeatedly return to both intervlews of the same participant and to interviews of other participants to gain clarity and validation regarding the presence, meaning, and significance of various themes. At the end of this process, the researcher had recorded fourteen pages of themes derived from the twenty-two interviews.

From these aggregate themes and after repeated in-depth encounters with the data the researcher began to determine the presence and organization of clusters of themes. These theme clusters emerged as central and unifying concepts for every participant. For example, every participant presented perspectives that pertained to the value of community health nursing activities. Activities then emerged as a central theme around which other themes clustered. The researcher validated these clusters of themes by referring back to the original descriptions. This was done to see if there was anything in the original data that was not accounted for in the clusters of themes, and whether the clusters proposed anything which was not in the original data. 
The researcher attempted to represent in the clusters of themes data that was comprehensive and true to the perspectives of all of the participants. Data that was not accounted for in the clusters of themes was deemed by the researcher as not significant to the participants. For example, a perspective offered by only one participant and in a superficial manner regarding the use of the Orem model in community health nursing practice was not included in the theme clusters. In addition, the researcher was careful to include in the theme clusters only the perspectives of the participants. The researcher continued to bracket personal perspectives throughout the analysis process so as to decrease the potential for researcher bias.

From this data analysis, the theme clusters began to coalesce around five central themes. For example, some of the theme clusters described the value of community health nursing in terms of activities, purposes, and prerequisites. Some of the themes clustered around the central theme of activities, and emerged as subthemes that were essential in explaining or clarifying aspects of that central theme. The central theme of the value of activities emerged as having two subthemes within it; this central theme and the subthemes within it are together considered a theme cluster. Four other theme clusters emerged from the data. Each central theme of these four clusters has subthemes that explain and clarify the essence of the theme. Collectively, these five theme clusters explicate the value of community health nursing from the perspective of the participants of this study.

The researcher then integrated the above data into an exhaustive description of the value of community health nursing. Within this description is 
the essential structure of the value of community health nursing as explicated by the community health nurse participants and as captured in the five theme clusters. Validation of this description as being representative of and "true" to the perceptions of the participants was done by returning to three of the participants in a third interview. The three participants validated the description as representative of their experiences and perceptions of the value of community health nursing.

\section{Reliability and Validity}

Reliability and validity of the study were addressed according to guidelines proposed by Sandelowski (1986). Reliability refers to the extent to which random variation may have influenced the study results (Field \& Morse, 1985). In qualitative research reliability is viewed in terms of consistency and auditability of the findings (Sandelowski, 1986).

This researcher ensured auditability was achieved by clearly denoting the "decision trail" used in arriving at conclusions such that another researcher could follow how this researcher arrived at decisions about the data. In addition, variations in community health nurses' experiences were sought by selecting nurse participants from each of the four health units. These various participant experiences and perceptions served to ensure that the theme clusters truly represented the value of community health nursing typically held by community health nurses in this urban center regardless of their unique work situations. For example, the perception by participants from all four of the health units regarding the value of teaching to community health nursing ensured that teaching emerged as a value. 
The various perceptions from the four health units also helped to ensure that each participant's unique perception or work situation would not unduly weight or influence the data. In addition, these various perspectives fostered a comprehensive understanding of the value of community health nursing, and not an understanding derived from only a few participants. For example, two participants from one health unit expressed perceptions regarding inadequate support from administration; two participants from another health unit expressed perceptions about the high degree of support they received from administration. By including both perceptions in the data, the researcher was able to obtain a more comprehensive and accurate picture of the value of community health nursing administration to community health nurses. This variation in experiences then contributed to a rich and reliable understanding of the value of community health nursing by ensuring the inclusion of perspectives from all health units.

Validity refers to how good an answer a study yields (Field \& Morse, 1985). In sound research, the answer to the research question should represent and not distort reality. Internal validity in qualitative studies is viewed in terms of truth value and credibility (Sandelowski, 1986). The researcher endeavoured to achieve credibility by presenting such faithful descriptions of the community health nurses' perceptions that other community health nurses who have similar perceptions would be immediately able to recognize those descriptions as their own. The credibility of the study also exists to the degree that other researchers or readers would be able to recognize the perceptions when confronted with them after having only read about them in the study. 
The researcher attempted to ensure the truth and credibility of the data by validating understanding with the participants throughout the interviews. For example, the researcher would reflect back to the participant the researcher's understanding of the participant's perspective, and then ask the participant if this reflected the participant's intended meaning. For example, one participant when discussing the value of government support stated, "...community health is very political - I mean you can't work in isolation of politics. You need their money and their support". The researcher reflected back her understanding of the participant's comment by stating, "What I hear you saying - and tell me if I'm wrong - is that a lot of what chns do is directed by others like clients and government." The participant agreed that the researcher understood her comment and added, "We may have something of value to offer as we see it but if the community and the government don't see it as a value, then we don't have a job really because the community and the government is [sic] not going to support us in our work if they don't value what we do."

A major threat to the internal validity in a qualitative study lies in the closeness of the researcher-subject relationship (Sandelowski, 1986). The researcher must avoid bias that would reduce the method to mere subjective interpretation. Keeping personal perspectives separate from participants' perspectives in a journal decreased this threat. In addition, the researcher validated the findings with participants during the interviews to ensure understanding from the participants' perspectives. In the third interviews, participants validated that the data analysis, understanding, and description achieved by the researcher reflected their perceptions, and were not biased. 
External validity refers to the generalizability of the findings and the representativeness of subjects and testing situations as they compare to conditions in the real world (Sandelowski, 1986). In qualitative studies there are fewer threats to external validity because these studies emphasize the study of phenomena in their natural settings with few controlling conditions (Sandelowski, 1986). Generalization is often not sought by qualitative methods; rather, phenomenology, as a qualitative method, seeks to accurately understand and describe the phenomenon under study (Sandelowski, 1986; Field \& Morse, 1985). In this study, accurate understanding was achieved by the researcher during each interview by clarifying with the participant the researcher's understanding of the participant's perceptions. In addition, the description of the value of community health nursing was validated by participants as accurate and true in the third interviews.

Subject representativeness, the second criterion of external validity, is defined as "any subject belonging to a specified group " (Sandelowski, 1986, p. 32). Any subject from this group who can describe well their experience is an appropriate subject for qualitative inquiry (Sandelowski, 1986). Therefore, in this study, the participants are appropriate subjects to describe the value of community health nursing since they meet specified inclusion and exclusion criteria and are members of the group of community health nurses who have lived and can describe this experience.

The ultimate evaluation of the external validity of a qualitative study rests with the fit of its findings (Sandelowski, 1986). A study meets the criterion of fittingness when its findings can "fit" into contexts outside the study situation 
and when its audience views its findings as meaningful and applicable in terms of their own experience (Sandelowski, 1986). Three study participants, who have also worked in other community health contexts, validated the fittingness of the findings in the third interviews. These participants stated that the findings were meaningful and representative of the value of community health nursing from their experiences and perceptions.

Another criterion of fittingness relates to the findings of the study and their fit with the data from which they were derived. The researcher endeavored to achieve this fittingness criterion by demonstrating clear connections between the data of the study and the findings by underlining and using arrows to connect the data and the meaning units and themes derived from that data. Examples have been provided in the discussion in this chapter to llluminate the fit between the data and the findings of this study. In addition, the findings are presented in Chapter Four using samples of the participants' perceptions to demonstrate the fit between the findings and the data of the study.

The researcher attempted to deal with the problem of elite bias (due to the selection of subjects who are the most articulate, accessible, or high-status) in a number of ways. First, the researcher ensured that community health nurses from each of the four health units were given the opportunity to participate in the study. Second, the researcher selected subjects with diverse experiences and backgrounds from the pool of community health nurses who volunteered to participate in the study. For example, two nurses with similar experiences in pediatric community health wished to participate in the study; only one was selected. Third, the researcher did not overweight any one "story", and placed 
each story in its proper perspective. For example, certain perspectives reflected that particular participant's unique experience in a health unit, or were a result of a health unit policy, personnel interactions, or program functioning at the time of the study. The researcher took these and other factors into consideration when analyzing and connecting the data and the descriptions so as to eliminate elite bias.

In addition to reliability and validity, Sandelowski (1986) discusses the criterion of neutrality in qualitative studies. Neutrality refers to the freedom from bias in the research process and product. This criterion in qualitative research refers to the truth and meaningfulness of the findings and not to the subjective or objective stance of the researcher. In qualitative studies, the meaningfulness of findings is achieved by reducing the distance between researcher and participant, and by eliminating artificial lines between subjective and objective reality (Sandelowski, 1986). Neutrality is achieved when reliability and validity as viewed in qualitative research and described above are established. The researcher's rigorous attention to reliability and validity as previously described facilitated the achievement of neutrality in this study.

Throughout the data collection and analysis processes the researcher sought guidance from experienced researchers. These researchers - the two thesis advisors - provided valuable feedback regarding the research process and the collection and analysis of data. By reviewing and commenting on various interviews and the researcher's analysis of these interviews, the thesis advisors helped the researcher to refine trigger questions to access data, and to reflect on 
and analyze data more effectively. Guidance from the thesis advisors therefore assisted the researcher to effectively implement the phenomenological method.

In summary, this chapter has provided a description of the phenomenological method and its use within this study. Specific applications of the phenomenological method to sample selection, data collection and analysis, and to reliability and validity segments of the study were presented. From this dialogical process five essential themes emerged as representing the essence of the value of community health nursing from the perspective of the study participants. These five themes are presented and discussed in the following chapter. 
CHAPTER 4: PRESENTATION AND DISCUSSION OF THE FINDINGS

From repeated in-depth reflection upon and analysis of the perceptions of participants, five central themes emerged as the essence of the value of community health nursing. This chapter presents each of these themes and their related subthemes in the context of the participants' perspectives. Themes and subthemes are then explored and discussed within the context of the conceptual framework of the study, namely values clarification theory, and with reference to relevant literature. Although each theme is addressed individually, an accurate understanding of the value of community health nursing from participants' perspectives must recognize the interconnected nature of each of these themes.

Prior to describing these themes, the researcher wishes to clarify that the role of each of the participants in this study was that of a community health nurse, and that participants entered this study valuing this role and the activities that facilitated the enactment of this role.

\section{Theme One: The Value of Activities in Community Health Nursing}

Every participant began the discussion of the value of community health nursing with descriptions of various activities. For example, in response to the researcher's initial invitation to present what she valued about community health nursing, one participant stated:

That's a huge question...Well, partly it's whatever attracted me to public health in the first place which was...an opportunity to engage in the kind of teaching about health and lifestyle and all the things that impinge on our health. Public health allows nurses to participate in teaching and maybe affecting people's attitudes in terms of lifestyle is probably what got me into public health and why I choose to remain. 
In addition, participants often referred back to and elaborated upon community health nursing activities in the first and second interviews. For example, the participant cited above referred back to activities later in the first interview and stated:

Counselling - that's one aspect of practice that I have always enjoyed. That actually was probably the second thing that motivated me other than the educational, teaching, and lifestyle kinds of stuff to enter public health.

This participant also referred back to and clarified the value of counselling activities in the second interview:

Well, if you look at counselling as the way that individuals interact with either other individuals or small groups, having counselling skills means bringing people in touch with a particular issue and what it is about their dynamic that may or may not be getting them an outcome that's wanted.

Therefore, activities emerged as central to the participants' value of community health nursing and thus became theme one: Community health nurses value multiple and varied activities that enable and empower clients to make informed decisions, choices, and actions regarding health and health care. Subtheme One: Collaborative Activities

In order to more fully comprehend theme one and its significance, various parts of the theme require elaboration. Two subthemes emerged from the interview data as providing this elaboration and clarity of understanding. The first subtheme describes the nature of the activities that participants valued, and is stated as follows: Community health nurses value collaborative activities that promote health and prevent illness.

Participants described a multitude of valued collaborative activities. Some of the activities that participants valued included teaching, facilitating, 
counselling, advocating, and communicating. Participants valued the enactment of these and many other health promotion and illness prevention activities within various cultural, environmental, social, psychological, economic, and political contexts. As one participant stated, " If we try and put a system in that they [clients] don't identify as valuable, it's bound to fail".

Participants elaborated on the nature of some of these activities in the light of, as one participant stated, "the new theories of health promotion":

The new theories of health promotion are more group related work, community based, getting the community together to address their needs and to say what they want and how they want it done and for us to be a resource to that which I...think is important and makes sense.

Participants valued community based activities because of their potential to be cost effective and to make more effective use of resources, including the expertise of community members and of community health nurses. Participants valued accessing and involving community members in health care as a way to enable and empower individuals and communities. By working collaboratively, participants believed that they and their clients could more effectively utilize their capabilities to effect health changes.

These views on the part of study participants are in accordance with views about the "new" public health expressed in the literature. Baum (1990) notes that the new public health is predicated on the belief that threats to the public's health are not confined to disease and lifestyle risks, but also emanate from social organization and structures. Baum (1990) suggests that change to improve the health of the public can best be achieved through consensus and collaboration. Labonte (1989) concurs and explicitly states, 'We must act upon the belief in our capacity, and the capacity of the people with whom we work, to 
create healthier environments for ourselves and for the broader community" (p. 23).

These and other authors who write about the new public health base their views on a seminal document, the Ottawa Charter for Health Promotion (1986). This document presents the essential characteristics of and prerequisites to the new public health. The value of community collaboration to enable and empower clients as expressed by participants in this study concurs with concepts about the new public health articulated in these sources.

However, participants also valued "the traditional programs which are the one to one home visits and immunization and vision and hearing followup the sort of standard programs that we do often on a one to one sort of basis". Participants believed that these traditional one to one activities had "made a difference" and that for some clients and for some health issues, group settings were not appropriate. For example, participants noted that some clients were less motivated or able to function in group settings due to culture, personal preference, lack of English language skills, and lack of funds for child care. Also, as one participant stated, one to one contact was often the way you "... got the community...The people in their homes that aren't connected to something or don't come out that much - that's how you reach them...that's where it starts". Participants valued a balance in their practice between traditional one to one activities and group and community based activities. Participants believed that this balance could best utilize the various capabilities of both the community health nurses and the clients to achieve health changes. 
The Canadian Public Health Association (CPHA) document (1990) that delineates the preparation and practice of community health nurses in Canada identifies diverse and multi-faceted community health nursing roles and activities. This document specifies two roles (health promotion, illness and injury prevention) and eleven activities (care/service provider, educator, consultant, community developer, facilitator, communicator, resource manager/planner/coordinator, team member/collaborator, researcher/evaluator, social marketer, and policy formulator).

Other authors also describe community health nursing roles and activities in a similar manner (Blank \& McElmurry, 1988; Chavigny \& Kroske, 1983; Maglacas, 1988; Tansey \& Lentz, 1988). Tansey and Lentz (1988) describe community health nursing as a specialty area within the nursing profession due to its holistic community perspective. They perceive community health nurses as generalists within that specialty because of their need to practice using knowledge from and competency in various clinical specialties, such as public health, nursing, and the social sciences. Participants in this study valued their roles and activities within a similar perspective, as this participant explains:

They're both actually. They are specialists in that they are doing community health...but when they are in community health, I think they are generalists...because we are dealing with people throughout their lifespan and in that way we are generalists, but just going into community health, we are specialists.

Participants valued their special blend of activities that emphasized prevention and health promotion within the community setting. They also valued the generalist perspective that involved them in health care throughout 
the life span of clients. Some participants stated that within this generalist perspective they could also develop specialist expertise, for example with a certain age group such as with toddlers or the elderly, or with a particular type of care such as breastfeeding or menopause counselling. Participants valued the variety and opportunities for professional growth that their specialist/generalist type of practice afforded them. As one participant stated, "I'm never bored".

Maglacas (1988) summarized the view held by many other authors as well as by the participants of this study, when she wrote that community health nursing has a role to play in addressing the inequities within our societies, in accessing and involving the public in all stages of health services. Recent government documents (Epp, 1986; The British Columbia Royal Commission on Health Care and Costs, 1991) agree that community health nurses should be important players in prevention and health promotion roles and activities. These sources have described roles and activities that concur with participants' descriptions of their valued roles and activities.

Subtheme Two: Autonomy

Participants valued autonomy, " the quality or state of being selfgoverning...self-directing freedom " (Webster's New Collegiate Dictionary, 1979), to the extent that autonomy emerged as subtheme two: Community health nurses value autonomy that facilitates effective and efficient community health nursing practice.

Participants valued autonomy because it provided them with selfdirecting freedom and control over decisions and actions - the what, where, 
when, how, and why of their community health nursing practice. One participant explained, "There's some opportunity for creativity if you are in control of a great deal of your work either in terms of scheduling it or developing programs". Creativity contributes to the creation of solutions to client problems within certain constraints, such as time. Creativity also contributes to an interesting work life, "It's just less boring".

Another participant spoke of the value of being " out there" where clients are. Participants explained that autonomy provides the opportunity to access clients where they are and when they require community health nursing care. The nature and needs of clients are the starting points of community health nursing decisions and actions. Participants deemed autonomy as essential in accessing and addressing client needs effectively and efficiently.

The researcher provides the following description as a summary of various participants' perspectives regarding the importance of autonomy. A community health nurse who has a school population as one of her clients will need to be accessible, at least some of the time, to students and teachers during school hours in order to enact some community health nursing activities. This same community health nurse may also be responsible for activities related to home visits, immunization clinics, mothers' groups, other community work such as interagency meetings, and the maintenance of connections at the health unit.

Some of these activities, such as immunization clinics, occur at regular times and places. Other activities, such as home visits, require a flexible schedule in order to be effective in addressing client needs when both the nurse 
and the client are available. Participants valued autonomy so that they could effectively and efficiently schedule activities within the contexts of their practices and the needs of clients.

Participants also valued autonomy because it allowed them to priorize activities and make decisions about the allocation of resources. This priority setting and decision making are necessary so that community health nurses can utilize their time and expertise to address client needs in a timely and appropriate manner. As one participant explained:

...the populations that I'm delivering the health care to are in their natural settings...I value that. I also value the independence that it gives me... I have to make the decisions that I go with at the time...I sort of go with it as it comes... Whereas in the hospital things are much more structured, many more constraints by policies and procedures and lack of time and resources, here I think we're a bit freer to use our resources as we see fit at the time. I value that...it's up to me to decide where my time goes or what programs I would like to promote and to evaluate what the community is looking for, too.

Riordan (1991) found that prestige and autonomy were linked to job satisfaction for community health nurses. Community health nurses are more satisfied if they perceive their work to be important and if it is held in high regard by others (Riordan, 1991). Participants stated that when they received input and support from colleagues and administrators that affirmed the value of their work, they felt motivated and empowered... "committed and full of energy and full of excitement...I am just so pleased and happy to work with [these] people...because they are just full of ideas and work like they're energized by what's happening." Collegial and administrative support fostered participants' autonomy, made them feel valued, and contributed to their commitment to remain with community health nursing. 
Theme Two: The Value of the Purposes of Community Health Nursing

Participants valued community health nursing for its ability to access a variety of clients in various contexts and attempt to include clients in their health care. These three concepts - client, context, and health - were expressed as valued purposes for community health nursing in the perceptions of the study participants. Each of these purposes will be discussed individually in the following sections.

\section{Subtheme One: The Client}

The first subtheme clarifies who participants identified as clients and client responsibilities: Community health nurses value the client (individual, family, group, or community) taking direct responsibility for determining and making decisions about needs, and for participating in health care to meet those needs.

Community health nurses perceive "client" in a broad manner. The use of the term "client" by community health nurses is itself illuminating. Webster's New Collegiate Dictionary (1979) defines client as " a person who engages the professional advice or services of another" (p. 206). This definition of client presents the receiver of services as self-determining and capable, and presents the provider of services in a professional consultative capacity. By using the term client rather than patient, community health nurses portray an enabling and empowering perception and expectation of both their clients and themselves. 
The client with whom community health nurses work can be not only an individual, as is characteristic of most other nursing care settings, but also a family, group, or community. As one participant explained:

...I do more than one thing and at different levels. So the one to one is satisfying personally because you get a chance to do the micro and then you take it to a much larger level and do the larger organizing - bigger things to get people to do things for themselves.

Participants valued the client variety in their work, not only in terms of the numbers of clients, but also in terms of the various cultures, capabilities, and needs of clients. This client variety provided a constantly changing and challenging work environment for the participants and required clarification of the nurses' values so that they could be effective. Also, client variety prevented repetition and boredom:

I am still learning and that's really important to me in that whatever position I'm in, I feel challenged... [Community health nursing] is still somewhat new to me... when it becomes too routine, I will go on to something else.

Whoever the client is has implications for the valuing, selection, and enactment of community health nursing activities. For example, one participant explained:

When I worked downtown, I had a large Chinese population - and it was promoting western health and also accepting the health care that they themselves used. Particularly with the Native Indians, you had to mix both; you had to let them continue with their own health care, but you also had to interweave within their own beliefs and value systems how you were going to work with them.

Participants valued helping clients become independent and effective in health care within the context of the client's culture and values; by definition, this necessitates involvement on the part of the client. To become involved, clients must see that their own values and priorities are acknowledged and 
valued by those who are part of the health care system, including community health nurses.

Steele and Harmon (1983) support the study participants' valuing of culture, and they emphasize the importance of culture in health care, "The health care services of persons from another culture are likely to be ignored if they neglect attention to the culture of the consumer" (p. 25). To effectively enable and empower clients, participants valued working with clients in determining what enabling and empowering health care means to them.

Subtheme one then points out the importance that participants placed on the various quantitative and qualitative characteristics of clients. This subtheme also describes the value participants placed on working with these clients in the context of their cultural and sociopolitical realities. This collaboration with various clients proved stimulating to participants and enhanced their feelings of personal and professional competence. As one participant explained:

...what I like best about community health is that you're working with all different ethnic groups and...different perspectives on people's beliefs and values and you yourself grow as a person.

Subtheme Two: Context of Practice

This subtheme clarifies the value participants placed on the context of their practice: Community health nurses value client contact in natural settings such as in homes, schools, and other settings.

Participants defined client as an individual, family, group, or community. Therefore, they valued activities that connected with clients wherever they might be. This may be part of the reason why participants valued the 
traditional one to one contacts as well as group and community development activities. However, participants realized that they could not continue the traditional, one to one activities and simply add community development to these activities. They would have to let go of some parts of their one to one work, and this would be difficult since they valued their traditional activities and were unfamiliar with this new role in community development. As one participant explained this struggle:

I don't know that we could eliminate the individual and family time...there's an imbalance, that that's all we do. And we're entrenched in the individual mode. And we're not doing enough on the other side of the coin... if we're going to focus on community development, there's got to be a major change in how we carry out our practice... That means providing less family and individual program time.

Another participant had further suggestions regarding the implementation of

both traditional one to one and community roles and activities:

But I think the two have to work together. I guess the issue is if you're doing lots of one to one you don't have time to look at the larger picture and the larger process of community development and being involved in that. We need to be asked where we want to be involved and how we can change...they're not mutually exclusive...it all sort of fits together.

These perspectives reveal that community health nurses are interested in and value the community development context, but they require involvement and support in clarifying and implementing this approach within the context of present community health nursing activities.

This subtheme also serves to underscore how community health nurses view their activities in the community context. One participant explained what client involvement in the community context meant to her:

...building on what is there as opposed to just going in and doing everything...motivating the community to get a handle on their smoking or drinking or heart attack or what have you... When I think about 
community development I think about making efforts to expand a group - to expand their ability to deal with problems that they have...I see [community development] as valuable because the way that problems get solved really is by people taking ownership of the problem and finding a solution that works for them...It doesn't work for me to lecture...that isn't going to do a whole lot in terms of changing behavior on a long term basis.

Other sources (CPHA, 1990; Pender, 1987c; Shamansky \& Pesznecker, 1991) also acknowledge the importance of various contexts or settings for the enactment of community health nursing activities. Shamansky and Pesznecker (1991) stated that a client such as a community can be both a target for help, a source of help, or both at the same time. Pender (1987c) suggested that multiple settings provide unique opportunities for community health nursing leadership in the design, development, implementation, and evaluation of health care programs. In addition, Pender (1987c) recognized increasing consumer support for quality of life and other health promotion programs. She urges community health nurses to access and capitalize on this interest. Subtheme Three: Health

From the participants' discussions, a specific definition of the health they valued emerged: Community health nurses value a holistic vision of health.

Participants described their practice as health oriented. They indicated health was more than the absence of disease. They felt that many determinants other than disease influenced their clients' health. One of these health determinants described by participants was the environment of the client, particularly the social environment. The social environment could include a 
host of variables, ranging from cultural factors to the number of individuals

and their roles in the client's social environment:

...there are all sorts of different things that influence their health and it happens mostly when they're at home and in the community...I think what we do a lot is support people in their roles, especially parents, and that's something that's really difficult and often overlooked...

Participants also described the psychology of the client as another determinant of health, and they addressed the nurse's role in relation to that determinant:

Understanding perhaps a little more of what the dynamic is that's happening with this person, why they're feeling so fragile or acknowledging that they're feeling fragile...conflict resolution also.

This participant identified listening, observation, intuition, sensitivity, and communication skills as being crucial to accessing the psychological status of clients. She spoke of the importance of having a mental health perspective of clients, rather than a mental illness perspective, "We have a lot of emotionally crippled people out there that aren't mentally ill at all and they have to grasp what mental health is".

Participants also realized that their holistic vision of health needed to take into account the economic realities of clients:

...middle class or lower middle class or lower income, they're more accepting of services, they're not so suspicious as upper class people...they're more willing to accept help, they seem to be more aware of community resources probably through word of mouth.

Another participant elaborated on the nature of the help sought by clients from various economic stratas of society:

People from the lower status tend to come to us just for help. Initially they don't really think about learning or teaching, they just want help. But if you can gain their trust, then slowly they start to learn and maybe you can see some change. But it's not easy. It's like one crisis after the 
next. Whereas for middle class - I'm making a general statement, it might not...apply to every family - they usually do a lot of searching, they have a lot of awareness...before they come to us...

This participant spoke about the economic and educational status of clients and the effect of those factors on health care:

...I've always worked with the lower income type of people who also lack education and they're very easily intimidated...I appreciate being an advocate for them, talking to people who they feel are intimidating, trying to get extra help for them.

Participants also described the relationship of physical variables such as nutrition and food, and client physical (dis)abilities and disease or lllness states to health:

For example, a flu - how to deal with those things because people go to you for solutions, answers, and suggestions. Something like diabetes, how do you manage a diabetic child, or seizures.

Other health determinants described by participants included client readiness to participate in health related activities, and the political environment - including the power positions - of clients. As one participant explained, "Being in the community, you have to be able to acknowledge that that person is getting along out there...they are doing it and so you're not the be-all and end-all for them".

The participants described health as an interactive vision between the community health nurse and the client. The vision of health may vary with each nurse-client interaction, given the different values and characteristics of the community health nurse and the client. For example age, culture, social milieu, and economic status were variables that participants felt significantly affected their own holistic vision of health and that of the client. 
Steele and Harmon (1983) stated that health is classifled as an instrumental value since good health leads to a life of quality. They have also stated that health is further defined as a social value which can only be judged in relation to other social values. These views regarding the value of health support the perceptions of participants in this study. In addition, Steele and Harmon (1983) noted that the value of the client as a holistic being is difficult to achieve in understaffed agencies. One of the participants also described this situation:

I tried to do a pilot project...for Chinese speaking people and we had several families that came. There was only four sessions and then we didn't continue because I didn't have time to continue doing it and we didn't have the extra funding to hire another CHN to relieve me from my usual duties...the number of public health nurses has been lowered...previously we had more positions and now we have less...but the population is increasing...

It is illuminating with regards to the purposes of community health nursing roles and activities to examine some definitions of health. First, it is important to note that no universally accepted definition of health presently exists (Pender, 1987b; Steele \& Harmon, 1983). Some of the reasons for this absence may be due to the following factors (Steele \& Harmon, 1983): (a) attributes of health and wellness are not determined, so accurate definitions of the attributes are not possible; (b) health is a culturally defined concept and cultures vary; and (c) health is a value or concept derived from the individual's cognition and ideas, making it multidimensional and difficult to measure.

Many of the definitions of health deal with stability, adaptation, and/or actualization (Pender, 1987b). Definitions of health that focus on the community can include any or all of these variables. For example, Tinkham, 
Voorhies, and McCarthy (1984) define community health as "those activities and concerns which are designed to enhance the quality of life and promote the well being of the total population in the community" (p. 180). This definition of community health seems to capture the purpose and goal of community health nursing as perceived by the participants of this study.

The World Health Organization (WHO) has defined health as "a state of complete physical, mental, and social well-being, and not just the absence of disease or infirmity" (CPHA, 1990, p. 20). WHO also believes that health is a resource for everyday living, influenced by circumstances, beliefs, culture, social, economic, and physical environments, and that the community/family/individual have a role to play in defining what health means to them (CPHA, 1990). These and other definitions reflect participants' perspectives of health in relation to the purposes of community health nursing.

Theme Three: The Value of Prerequisites for Community Health Nursing

Participants spoke of certain prerequisites that they believed were necessary for the effective enactment of community health nursing activities and purposes. These prerequisites are each discussed in the following two subthemes.

Subtheme One: Knowledge

This subtheme addresses one requirement that participants valued for effective decision-making and action-taking: Community health nurses value a broad knowledge base. Participants in this study valued knowledge from various sources because, as one participant explained:

...it gives you a broader base of understanding of human nature, human kind, and anything that can do that will make you more sensitive to 
community...when I think of broader I think of...arts courses, english, history and some sciences and some psychology and sociology and anthropology - all those things that can't help but give you a wider understanding of humanity and our civilization.

The knowledge identified as valuable by participants was often difficult to attribute to a specific discipline due to the overlapping and interdependent nature of the disciplines and the interdependent use of knowledge by community health nurses. For example, knowledge related to effective communication was cited as valuable. However, various disciplines could be sources of such knowledge. Nevertheless, from participants' descriptions of the knowledge and the purposes for which the knowledge was used, nursing, public health, and the arts and humanities emerged as the primary sources of formal knowledge valued by community health nurses. When discussing the knowledge they valued, participants often referred back to their own practice and evaluated the importance of particular knowledge to their practice.

Participants valued a university education because they viewed the university context as integral to the valued knowledge base. They believed learning in a university context facilitates critical thinking and problem solving which they also valued. As one participant stated:

I think that [baccalaureate degree] also affects how you see yourself and your job...thinking skills and organizing skills can help you put a different slant on things instead of doing things because we've always done them this way - you're looking at what alternatives are available and how you can change them.

Knowledge from nursing that participants valued included information from the nursing perspective about the care and treatment of diseases and illnesses. While this type of knowledge may seem incongruent for a practice that is prevention oriented, participants noted that clients do come to 
community health nurses for "solutions, answers, and suggestions" on how to deal with conditions such as "the flu, diabetes, or seizures". Other valued knowledge from nursing included information about human growth and development, maternal-child interaction, mental health and mental illness, nursing research, and knowledge about what it means to do community health nursing - the history, art, science, and practical implications of community health nursing practice.

Although participants did value knowledge from nursing, they seemed to place more emphasis on the knowledge and application of knowledge from public health. Some participants even suggested that the word nurse be dropped from their title and that they be called community health practitioners or some other title instead. When asked by the researcher for the reason for this suggestion, a participant explained, "I was Just thinking of the association we have with 'nurse' which is nurse gives shots, nurse maybe weighs bables, nurse takes doctor's orders, nurse works in a hospital". This and similar responses indicated that participants viewed themselves and their work in other than the traditional images associated with nursing in a hospital setting. Knowledge valued from public health included knowledge about epidemiology, communicable diseases, community assessment, various determinants of health, health promotion and disease prevention concepts and practices, and knowledge about community development.

Participants also valued knowledge from disciplines other than nursing and public health. They believed that knowledge from other disciplines helped them address the broader issues in community health nursing, and helped 
them understand the "big picture" of health and health care. Participants valued knowledge from psychology, sociology, history, english, anthropology, commerce, adult education, and other liberal arts and humanities disciplines. In addition, participants valued knowledge related to such topics as health care organizations and policy, politics and government, technology, culture, and the environment. Participants welcomed knowledge from disciplines that would help them address the needs of clients.

Participants also valued informal knowledge gained over time from diverse community health nursing experiences. This knowledge they termed intuition, or a gut feeling. Participants valued this intuitive knowledge for the direction it could provide in assessment and other client interactions. For example, when describing her work with stressed families who ventilate their frustrations at the community health nurse making a home visit, one participant spoke about how intuition, gained from experience, helps her to anticipate and deal with these situations:

I was not the one that they were angry at but they just had to let out their anger, to have some ventilation...I didn't feel too bad. I made myself ready, I kind of expected that it might happen. So I kind of planned ahead of time that that could be one of the outcomes, then I would not be so frustrated.

Another participant spoke about why intuition was valuable to her:

...listening and observation skills and those intuitive skills...being sensitive to the moment for whatever the moment is for people, because that's part of nursing...sensitivity to wherever a person is at on a level that maybe they might not be conscious of. Understanding perhaps a little more of what the dynamic is that's happening with this person...

The knowledge valued by participants in this study reflects knowledge cited as important by others. Skill levels and concepts required for community 
health nursing are quite different from the acute care setting (Kenyon et al., 1990). Theoretical and experiential components must include concepts related to assessment, intervention, and evaluation effective within the community setting, decision making, case management, prevention and health promotion, epidemiology, social policy, and the history and philosophy of public health, and many other concepts (Blank \& McElmurry, 1988; Deiman, Jones, \& Davis, 1988; Kenyon et al., 1990; Williams, 1977).

Many authors have recommended that clinical experience in community health is best achieved using role models from practice settings and instructors with relevant and adequate community health nursing experience to guide student learning (Deiman, Jones, \& Davis, 1988; Salmon, 1989; Salmon, Riportella-Muller, \& Selby, 1991). Furthermore, collaboration between the practice and education settings is encouraged to keep community health nursing education current and relevant (Barkauskas, 1982).

The Canadian Public Health Association (1990) has affirmed that knowledge from nursing, public health, and other disciplines is required for competent community health nursing practice. As Kenyon et al. (1990) have noted, the complexity and broadness of scope of community health nursing practice require practitioners who have a broad base of education and who can function independently in this advanced area of practice. Perceptions by participants in this study reflect knowledge requirements that are similar to perspectives offered in the literature. 
Subtheme Two: Personal Qualities and Attitudes

Participants indicated that having the knowledge necessary to practice community health nursing was not in itself sufficient; something more was required. This something more emerged as subtheme two: Community health nurses value certain personal qualities and attitudes that help them effectively achieve their responsibilities. Participants elaborated on this value by discussing the independent nature of their work and personal attributes they valued to facilitate their work. Some of these included: assertiveness, confidence, self-directedness, empathy, respect for clients and colleagues, flexibility, receptivity to change, creativity, risk-taking, and a sense of humor.

Participants' perceptions clarify the value they attributed to these personal qualities and attitudes. The three most important qualities that one participant identified included firstly, communication - the ability to talk with and listen to numerous and varied people, followed by:

...attitude is the next...You can have your own set of values and attitudes but it is the willingness to accept other people's values and attitudes...to have the attitude of 'I want to hear what you say and I may not agree with it but you are allowed to have that viewpoint'...the community is not going to change just because you stand up there and scream your values.

And thirdly:

a sense of humor that allows you to find an escape...because a lot of the stuff you deal with is really too difficult for one person to be taking inside all the time.

Participants addressed the need to be assertive about the community health nursing role and activities, particularly in the school environment. Participants felt assertiveness was critical to demonstrate to school personnel the capabilities of community health nurses: 
...what they really want in the schools is someone to put on bandaids. And once I point out to these people...that I have a university education, $\mathrm{x}$ number of degrees and so on and do you really think my goal in life is to put bandaids on cuts? Then something twigs...they see the nature of my work in the school now...and they're quite amazed at the diversity of the work that we do. While we're doing bandaids, we're also doing individual counselling, getting in touch with families, doing vision screening...everybody resents first aid and somehow they just figure they can dump it on the nurse...and at some point in my own nursing career I decided, forget this, I'm not getting dumped on.

Other participants also described being assertive:

...you have to speak up. So often I see people just waiting for other people to come to them. Well, nobody knows to come to you if you don't speak up. You have to say, you have to be out there, you have to put it out, 'This is what I can do, this is how I can help you'... If you're a little bit shy and retiring and you hold all that information inside, nobody is going to guess and nobody is going to ask you. You've got to kind of sell it.

Participants also spoke about the value of flexibility and adaptability,

particularly in stressful family situations, and of respecting the perspective of

the client:

Sometimes we work with families who are under a lot of stress...We are like the first person they come in contact with...to have some ventilation. And sometimes they get mad at you, not because of you, but they use you as an avenue to let out steam. And I've found on several occasions that I was not the one that they were angry at but they just had to let out their anger and afterwards they apologized and we had some decent conversation going. And we might reach a solution or see where the problem was...

In addition, participants described using empathy, collegiality, and flexibility:

...to be able to sit back and allow the clients to be able to tell you what they want and to be able to try and give to them without saying this is what they have to do...recognition of the client's needs...and just recognition of utilizing your colleagues, gaining some expertise from them and sharing some of what you have...and to recognize that there's no one way to do something.

Participants emphasized the value of certain personal qualities and attitudes in terms of dealing with the successes, frustrations, and challenges of 
community health nursing activities. For example, autonomy in community health nursing practice requires practitioners who are comfortable and can function effectively in such an environment. To facilitate this autonomous functioning, study participants emphasized the value of support from others, particularly from colleagues and administration. In response to the researcher's question as to why this input and support were important, this participant echoed the responses of many of the participants when she replied:

This is quite a stressful job - there's no one to pick up for you when you go out there into that home or school, no one else is doing your job, you're the one that's responsible. All that assessment has to be done by you; those skills have to be working and have to be honed and you have to be aware of so many areas.

These and other comments by participants indicated the nature of the demands placed upon an autonomous community health nursing practice. In order to cope with these demands and capitalize on the possibilities of an autonomous practice, participants relied on their colleagues and administrators for input and support.

From colleagues, participants valued input and support that was enabling and empowering for each other, and also that provided some "care for the caregiver". The autonomous nature of their work means that each nurse may be the only health professional working with a large population of clients, such as in a school. This leads to feelings of isolation. In dealing with an autonomous practice that may include feelings of isolation, participants valued from their colleagues insight, empathy, trust, expertise, and simply being together as a cohesive group with similar goals and values. As one participant explained: 
I get out there, I do my own thing in an environment of 2000 people of which I am the only nurse. It is very important for me to come back and be able to listen to my colleagues and how their days have gone and to be able to understand totally what they're talking about and to be able to share my own stories and to know that people are understanding, to gain the insight and access to information that they have.

Steele and Harmon (1983) discuss the importance of the collegial or referent group in terms of nursing and values clarification. These authors state that clarification of personal, client, and professional values is necessary in order to determine the value structure upon which nursing decisions and interventions are based.

One method useful in achieving values clarification is to discuss with colleagues the value-laden situations faced in professional interactions (Steele and Harmon, 1983). One outcome of such collegial interactions is the development of empathy for clients. Another possible outcome is an appreciation on the part of each group member for the value of ranking their own priorities differently in order to be compatible with the group's value structure (Steele \& Harmon, 1983).

Steele \& Harmon (1983) explain that participation in this values clarification process helps prepare nurses for the decision-making process in specific client situations where value-laden decisions must be made. Community health nurses face many situations that demand value-laden decisions and priorities. Examples of such situations that participants provided in this study include: doing first aid versus doing health education in schools, the value of traditional one to one programs versus the value of group programs, what the client values versus what the nurse values. As Steele and Harmon (1983) and the participants in this study point out, community health 
nurses can benefit and grow from collegial input and support; effective decision-making is fostered when it is enhanced by a process of referent group values clarification.

Participants also valued input and support from knowledgeable administrators who value community health nurses' activities:

The really good administrator is able to look for the special skills that their staff, that each individual brings and help that nurse develop those things...good administrators don't hover over people. You're very clear about what's expected of you and...then you go and do your work. Good administrators are able to offer possibilities to staff people that the staff don't even think of themselves, so there are opportunities for really growing and stretching and expanding horizons...

Someone who understands the program and what we're here for, someone who imparts that information...someone who's supportive of their staff. Someone who's got a knowledge base about community health so that she can be an educator for her staff...someone who's going to let nurses get out there and do their jobs, and leave the door open so I can come back...Someone who can help to go through the decision making process...that sense of responsibility for your practice and that gets supported by the administration. Higher than that, I think our administrators need to be looking more at professionally developing us...just setting time aside for us...

Participants valued administrators who effectively promoted the value of community health nursing activities among nurses, as well as within nonnursing environments. Participants noted that in these times of economic restraint, when preventive services are often the first to be cut in funding, effective leaders in community health are needed to maintain resources. If resources could not be maintained, participants realized that some of their programs also could not be effectively maintained, and this contributed to low morale and feelings of dissatisfaction on the part of community health nurses. Furthermore, participants believed that limiting programs also limits the public's perception of the value of community health nursing. In accordance 
with these views, Josten (1989) noted that in addition to resources and public recognition and support, community health nursing needs effective leadership to communicate the value of health programs, develop skills in political coalition building and community organization, and earn the community's trust.

Steele and Harmon (1983) have stated that a commitment to particular values necessitates a corresponding allocation of time, energy, and resources to support the values that are selected. When community health nursing administrators have the authority to allocate resources, participants believed that it is important that the administrators' values and the community health nurses' values be congruent. This congruency would facilitate administrative decisions that would support community health nursing decisions and actions, for example in the areas of financial and other types of support for programs.

A review of some of the underlying factors impacting on the community health nursing role and activities may help to clarify why personal qualities and attitudes are valued by the participants of this study.

A critical and pervasive factor which impacts on community health nursing practice particularly in large urban centers is that of cultural diversity. Each culture and its individuals hold values regarding health and life style, and beliefs about the roles and responsibilities of clients and professionals in health care. Most authors suggest that community health nurses must be sensitive to other cultural value systems, whether or not these are congruent with the nurse's value system. Participants also believed that they needed certain 
personal qualities and attitudes in order to deal effectively with value differences and conflicts.

Another significant factor that impacts upon community health nursing in Canada is that of funding for preventive services and programs. Canadian health care funding continues to value and favor curative over preventive services (Matuk \& Horsburgh, 1989). Because community health nurses work within a treatment oriented environment, they need creative approaches and the sharing of collegial successes in order to facilitate the valuing of prevention: ...there's some opportunity for creativity...either in terms of scheduling or developing programs...to get something off the ground. There can be lots of constraints to being creative...budget issues so you may not be able to have the kinds of equipment that you want or the kind of PR that's necessary.... if you come up with something that's quite creative then it's very often very different from what's in existence. So you may have to do some major selling. Taking a risk...

Participants valued collegial and administrative input and support that facilitated creative approaches, risk taking, and trying something new, particularly when government support for traditional programs was not secure. These types of creative approaches to deal with government priorities require practitioners who have certain personal qualities and attitudes.

The personal qualities and attitudes valued by participants in this study reinforce and support valued community health nursing activities. This internal affirmation of values can be particularly important as community health nurses attempt to enact roles and activities that may not be valued or acknowledged in their work environments or by their clients. In addition, because community health nurses function independently and may be the only health professionals providing care for large populations of clients, practitioners must be self- 
reliant, self-directing, and self-affirming. The personal qualities identified by the participants in this study underlay the independent activities they undertake. These personal qualities also assist community health nurses to remain clear about and committed to the value of their work and therefore facilitate the effectiveness of community health nursing practice.

In conclusion, themes one, two, and three indicate the study participants' valuing of the nature and purposes of their practice, and prerequisites for effective practice. Participants were eager to discuss the uniquenesses and similarities of each of their nursing practices. Some of the participants remarked that their discussions about the value of community health nursing helped them to look more critically at what they are doing, and why they are doing it.

Theme Four: The Value of the Visibility of Community Health Nursing

Participants indicated that clients and others have direct control over the selection, utilization, and support of community health nursing services.

Participants linked the visibility of their activities to their clients' utilization and support of their activities. One participant observed:

People don't know us...A majority of them aren't [aware of us] unless they've had contact and even with the contact they may remember at the time but as years go by they say, "Well, someone did come by to see the baby". But that is all they know...

Participants also noted that visibility was a factor in government support for community health nursing programs:

Absolutely [government undervalues us]. Oh, what do you do? It's very invisible, it's very invisible. You get a lot more votes for building a 20 storey building on 12 th and Oak you know. 
Visibility then emerged as theme four: Community health nurses value community health nursing that is visible. Two subthemes clarify the nature of and reasons for the value of visibility from participants' perspectives.

Subtheme One: Others' Awareness and Valuing

Participants hoped that others, for example clients, nurses who do not work in preventive community health, and the public in general, would value community health nursing services if they were visible. They believed awareness would increase the value and the use of community health nursing services. Subtheme one therefore emerged as follows: Community health nurses value others' awareness and valuing of community health nursing services because they believe awareness and valuing will facilitate effective use of these services.

Participants believed that many people were not aware of their services and only valued them after they received them. As one participant stated, "They are pleased, they didn't know you were there, they think, oh, isn't this great...But they didn't know you existed until you showed up at their door". Participants also valued visibility because they believed visible services were more competitive with other resources. In addition, visibility increased participants' perceptions of being valued. This was evident in the proud and confident way that a participant explained her part in initiating a new program:

I think of...when the school lunches were starting - myself and another school nurse were both in inner city schools. And the media wanted to hear what we had to say. We did a presentation to the school board about what we saw as nurses in our schools... and the media were coming up and saying, "You're the nurse, tell us more, tell us more. Can we quote you on this, will you appear on radio?" And we ended up on $\mathrm{CBC}$ and CJOR. 
Participants believed that a lack of visibility was particularly true of urban community health nursing. More than one participant had perceptions similar to the following:

It is really hard in a huge community like [this] to feel valued because there are so many other resources going around that people don't necessarily a) know that you exist or b) see you as a valuable resource. When I worked up north...I got a sense of feeling valued from the community. I was seen as the expert person, the person to come to before you went to a doctor, valued by the doctors for the knowledge that I had and the referral skills that I could use and you felt like you were part of the community. The community knew who you were and they thought your service was a good service...You are more visible in the community as a member there...

Participants stated that their role was not always clear to clients and the public. Participants perceived that this lack of role clarity was due in part to the invisible nature of various community health nursing activities. In their school work, for example, participants spoke of activities such as doing home visits to families of school children, referring of students to other disciplines, and student counselling. These activities are often not visible, and therefore expectations of the community health nurse by school personnel may often be limited to visible activities such as first aid, communicable disease screening, or even as a replacement for secretary or teacher activities. This lack of role visibility and clarity and the resulting lack of appreciation for the value of community health nursing capabilities frequently lead to frustration on the part of participants. In dealing with this frustration, participants described their valuing of assertiveness and coalition building:

This was my third fall [in this school]...I got working right away...I go to the staff at the beginning of the year...with the counsellor because we work quite closely together and we told the staff what we were prepared to do... the things that we could do and add and the kinds of resources we had...how we could augment what they did.... what our capabilities 
were...you have to speak up...nobody knows to come to you if you don't speak up.

I'm working with an administrator right now who's been in the system a long time so recognizes the value of nurses in the school. There's still the steady battle of nurses in the schools, like...what our role is. It's not a first aid person...But I'm quite sticky about that so I don't let people get away with it.

Participants also valued visibility because of its potential to decrease role fragmentation. Clients have contact with a community health nurse in one or perhaps two roles - during a postnatal home visit and in a school for example. The other community health nursing roles and activities may not be visible to clients because they do not access the nurse functioning in those roles, for example, in counselling, referral, interagency meetings, or other activities. One participant noted:

Public health nurses - who are you? Someone out on the street [may] know who the school nurse is...landl "someone did come to see the baby" but that is all they know, they don't see the whole role, the expanded role.

Clients may also not be aware that it was the community health nurse who initiated care on their behalf. Therefore, the multi-faceted value of community health nursing roles and activities is often not evident to clients.

In addition, participants valued visibility because they believed it could help to prevent role erosion. Recent hospital programs in this metropolitan center have initiated early discharge programs for postnatal women with followup by hospital nurses, rather than by community health nurses. Participants felt this expectation was inappropriate and an encroachment on their expertise that might have been prevented by increased visibility. As one participant noted: 
We in the community like the idea of support to the client, but we don't like the idea of having hospital nurses doing our job, visiting the mothers...we are trained to work in the community. We know better about resources...We have the skills and information and...it's not the greatest use of the budget... Why not use the group, ourselves, that are already there...just give the budget dollars to community health nurses.

Within the context of an illness and treatment oriented society, it is not surprising that participants identified the need to promote the value of their work in health promotion and lllness prevention in terms of increased visibility. If clients are not aware of community health nursing services, then they will not value, select or use these services. Martin, White, and Hansen (1989) discussed community health nursing invisibility and its impact on health care and they recommended, "If nursing is ever to mobilize its collective power to influence change in public health care policy, it will first have to reverse its invisibility as a major contributor to effective health care" (p. 92). The nurses in this study also spoke of their collective power to influence health care policy and decisions as a result of their visibility in terms of numbers:

I think that [our] numbers are big enough, like I believe that if you believe in something strong enough and you have enough numbers that you can actually make a difference and I think that you can stand up [and] say that...and then hopefully get the backing of administration as well.

Participants suggested ways to promote their visibility: individual and collective discussion and promotion of their value at work, involvement in the Community Health Nurses Group of the RNABC, and effective use of the media to promote their value and visibility to clients and the public. However, participants also noted impediments to their ability to promote their visibility: lack of time and other opportunities during work hours to develop and 
implement strategies that promote visibility, and a sense of apathy on the part of some community health nurses.

Jarvis (1985) urged community health nurses to promote their specialty in the areas of prevention and health promotion with a distinct philosophy, goals, services, and boundaries. If the value of community health nursing is not made visible, and if role fragmentation and erosion persist, then community health nursing may lose whatever position it holds in prevention and health promotion, and may cease to exist (Chavigny \& Kroske, 1983; Clarke, Beddome, \& Whyte, 1990; Matuk \& Horsburgh, 1989). Participants also expressed concern about the persistent threats of termination of community health nursing positions and programs by government funding agencies. They felt that the invisible nature of community health nursing activities contributed to this constant threat.

Participants also valued the visibility of community health nursing to nurses who do not work in prevention settings. However, they believed that these nurses were often not aware of and did not value community health nursing roles and activities. They perceived that hospital nurses often did not value them as real nurses:

I have had some contact with hospital nurses...and some home care nurses and... [they] look upon public health nurses as 'desk' nurses, they don't see us as doing anything else...she's a 'desk' nurse, what does she know, what does [she] do. They don't see us as really being nurses because nursing to them is the medical model.

Participants attributed this lack of awareness and valuing to a number of factors: nursing education, particularly in diploma schools, that does not sufficiently or appropriately sensitize students to community health nursing, 
lack of experience on the part of hospital nurses in the field of community

health nursing, and lack of contact and communication between community

health nurses and hospital nurses:

There's not much information sharing between hospital nurses and community health nurses...I haven't seen any joint meetings between the two groups...For nurses in the community, we know what hospital nurses do because usually we've worked in hospitals before we switched over to community health. But not the other way around.

Participants noted that they felt valued when hospital nurses used community health nursing services appropriately, such as when making referrals. However, they noted the need for opportunities for contact and dialogue between community health nurses and hospital nurses to discuss their work and work together more effectively.

Participants also noted an appreciation of community health nursing was not readily apparent in other groups of nurses such as the British Columbia Nurses Union (BCNU) and the Registered Nurses Association of British Columbia (RNABC):

[the value of community health nursing within RNABC and BCNU] is not great but that's because out of 30,000 or 35,000 nurses in $B C$, how many are employed in community health?...my personal bias is at the RNABC, they seem to have a more health oriented position as opposed to a cure position. The BCNU, well they definitely look at where are the members coming from...I'd just like us to be heard from more, the point of view of prevention expressed more strongly.

Participants felt that this lack of appreciation was due to the small numbers of community health nurses and the preponderance of acute care and other nurses in these organizations. However, as this quote illustrates, participants also noted that community health nurses have a responsibility to promote their own visibility and value within these organizations. 
Participants valued community health nursing education for its potential to make visible the value of community health nursing to all nurses, thereby fostering improved understanding and utilization of the expertise of each other. In addition, they believed that this education would foster confidence in new practitioners and encourage them to choose community health nursing as their area of practice:

I think it is an explanation of why there are so few nurses coming into community after they get their baccalaureate - it is because they haven't had the exposure to be really comfortable to say, "This is something I can see myself doing". They are much more exposed to hospital nursing and it is safe to go into that because you really do know what is going on. Community is the great unknown stuff.

These perceptions about the value of adequately and appropriately facilitating the education of students in community health nursing are supported in various sources (Bell \& Wright, 1990; Chavigny \& Kroske, 1983; Deiman, Jones, \& Davis, 1988; Kenyon et al., 1990; Salmon, 1989; Salmon, Riportella-Muller, \& Selby, 1991; Williams, 1981). These authors concluded that nursing education priorities should include: the clear articulation of community health nursing concepts and theories, and opportunities for the enactment of these theories in appropriate community health nursing settings with guidance from adequately prepared instructors. These requirements are needed so that students can later function effectively in both hospital and community settings. Visibility of community health nursing concepts and practice within nursing education programs then, has implications for the effectiveness of nursing in other practice areas as well.

Recent developments in British Columbia may foster the visibility and value of community health nursing. The new program developed by RNABC - 
New Directions for Health Care (RNABC, 1992b) - may help to draw the attention of all nurses in British Columbia to the importance of health promotion and illness prevention. The report of the British Columbia Royal Commission on Health Care and Costs (1991) was valued by participants as a significant step forward in making visible to the public and to the government the value of illness prevention and health promotion.

Subtheme Two: Political Visibility

A second subtheme emerged as participants discussed the importance of government support to the maintenance and promotion of community health nursing services and programs. Participants believed that while federal and provincial governments verbally endorsed preventive philosophies and services, they often did not follow through with consistent financial and other essential support for these programs:

People give [prevention and health promotion] lip service but...it's well known it doesn't get votes. A new MRI machine or a scanner will get votes but will people vote for the politician who says we're going to make sure that we have a really powerful ant1-smoking program in this province...Not likely. Not likely.

Participants felt that a lack in community health nursing visibility was partly responsible for this lack of support. Therefore subtheme two emerged as follows: Community health nurses value visibility in relation to governments because they link visibility to government support for community health nursing services and programs.

Participants noted the continued preference of governments to support acute care agencies. However, participants saw a need for more community health programs and more government support for prevention: 
If you are really going to get into this meeting the needs of the community...we have to have more programs...programs could be expanded but that needs more money...I would like the commitment from government that they do see the value in what we do. That they do see the value of preventing health concerns.

Participants noted that funding for prevention and health promotion services and programs was the first to be cut when financial constraints were deemed necessary by governments:

I find it frustrating that we are always or very, very frequently the low man on the totem pole when it comes to the greater picture...Prevention in the Ministry of Health's budget is not highly rated and highly valued...that's what results in chns often being stuck with old information systems, old ways of doing things, old equipment, and being way, way behind the times... we've never got the money we asked for to change and so we're still doing it [the old] way.

This unreliability of funding contributed to participants feeling undervalued by governments. They had seen effective community health nursing programs abandoned due to government cutbacks. Some participants expressed the view that they were reluctant to develop and initiate new programs, even if they had every reason to succeed, because they were uncertain about the long term commitment on the part of governments to support such programs.

Part of the rationale for government funding priorities, participants felt, was related to the election dependent nature of government and political offices and appointments. As a consequence, they believed that short term and visible results are given priority by governments to prove the merits of political decisions and actions:

Governments don't look to the long term...they're looking to a more short term return because they do have to answer to the people in an election which happens every 3 or 4 or 5 years. So they want to see something in 5 years so they can say. "See what we built or see what we've done". 
Participants noted that government priorities often did not fit well with community health nursing goals and activities, which are often oriented to the long term, have outcomes that are difficult to measure, and which are frequently invisible in nature:

Governments are much more into counting numbers and adding up figures...governments like to see some sort of cost return so...they can see what they've got for their money. In public health, it's not there, you can't really see something that's been built, a structure. With health promotion, you can't see the money you've saved in the end...[governments] forget to look down the road 15 years...

Participants valued political visibility on the part of community health nurses because they felt it would increase their involvement with and value to governments, and ensure consistent and reliable funding for their programs. Participants suggested that they could be politically active through the Community Health Nurses Group of the RNABC to collectively promote local, regional, provincial, and national community health nursing issues.

Participants also noted that community health nurses should seek and serve in positions that are instrumental in promoting the value of community health nursing. One participant stated:

I really have to get extremely political, extremely involved. We have to get extremely political...go for Assistant Deputy Health Minister - that's what we need. We need to have people at that level who are actually nurses.

Another participant explained why being politically active is valuable for community health nurses:

I don't think every nurse has to be active but as a collective group, yes...because that's where the decisions are often made as to how things will be allocated...and [they are] not always necessarily [made by] people that actually have the needs or the knowledge. 
Participants believed that they had valuable knowledge to contribute to the political process, knowledge that they had gained from direct contact with clients and client needs, and that could effectively inform policy discussions and decisions. However, they also recognized a need for knowledge in such areas as lobbying. Even so, the subtheme of political visibility, of having and using a community health nursing voice that is heard, was valued by participants as a way to raise their profile and their value within government circles. In this way, participants hoped to ensure consistent and reliable support from governments for the maintenance and development of effective community health nursing programs and services.

Chavigny \& Kroske (1983) observed that community health nursing services were the first to be discontinued when fiscal cutbacks became necessary. Graham (1989) stated that a potential outcome of cutting costs is that "eventually the buildings remain but the people are gone" (p. 161). She goes on to assert that the greatest capital of any organization is its human capital because human beings remain the idea generators and the resource for getting the job done. This is certainly true in the practice of community health nursing, with its focus on people, and the need for creativity in helping them develop healthy life situations. Graham (1989) urged community health nurses to be risk takers and leaders in promoting changes within the health care system, and in surmounting barriers to change. The political activism suggested by participants in this study concurs with these authors' admonishments for leadership and risk taking roles for community health nurses. 
Theme Five: The Value of Community Health Nursing

as the Way to the Future

Participants expressed a future oriented value of community health nursing. This perspective was based on participants' realization that health care costs could not be maintained at their present levels. In addition, participants believed that prevention of disease and health promotion, not treatment after disease (particularly preventable disease), should be the focus of the health care system. Participants believed that this focus would contribute to improved quality of life as well as decreased costs to the health care system. Therefore theme five emerged as follows: Community health nurses value community health nursing as the way to the future in health care. This theme is further clarified in the following two subthemes.

Subtheme One: Prevention and Cost-effective Bases

The first subtheme emerged from the data as follows: Community health nurses value the preventive focus and the cost-effectiveness of community health nursing as the bases for this future health care orientation. As one participant explained:

I think [community health nursing] is an important thing for nurses to be going into and it is certainly much more the way to the future than building more hospital towers - in terms of capital expenditures alone, it's way more cost effective. We are really good at assessing the needs of the learners and directing what we are trying to teach towards those needs and...that's the way health care has to go because we just can't afford it the way it is right now...

Another participant stated that the reason she stays with community health is "because I see its potential as being on the cutting edge". She clarified what she meant by 'cutting edge': 
There's that aspect of prevention...people are acknowledging, identifying, determining, deciding that if we can prevent the disease process we have healthier people. We cut down on costs...So [community health is] on the cutting edge of all of that...in the past 3 to 5 years...there's been more lip service to grass roots health care again, taking things back to the community, community development - what that means in all aspects of our lives...Certainly within the department, everybody's looking at it and what it means to us and how we're going to best serve our communities...So that's why I say it's on the cutting edge.

Participants recognized that the health care system could not afford to continue emphasizing acute care and treatment; the financial costs alone for such care are becoming prohibitive. Furthermore, participants did not hold to a treatment philosophy. They believed that health and quality of life were better served by preventing disease and injury and by promoting health:

...the value of preventing health concerns...a lot of that is social issues... it goes so far beyond just the healthy issues - that we can't have healthy people without healthy societies and that means safe streets and good water supplies and good schools and parks that kids can play in safely and that's all tied to it...

By helping to keep people healthy and out of hospitals, participants

believed they could help to decrease costs to the health care system and contribute to a better quality of life for clients. Community development approaches were seen by participants as cost-effective because they accessed groups rather than individuals. These approaches therefore can make more effective use of community health nurses' time and expertise for those clients who are able and willing to interact in group environments. Participants also suggested an expanded role for community health nurses in the future as the entry point to the health care system:

We can be the leaders in directing things away from the doctor being the entry point and the hospital being the 'be all' and 'end all' of health care. But we do need to be more mouthy about it and let people know. 
Another participant suggested a particular expanded role for community health nurses in her urban center:

...the government needs to look at prevention in a different light...the prevention nurses could really decrease the cost of the health care system if the government recognized the value of community health and what the nurses do. For example, get rid of these doctors who are doing CHCs...Don't let doctors [here] give their own immunizations. Let nurses do it. That's what the province does - they don't allow doctors in the province to have the toxoids.

Matuk and Horsburgh (1989) have stated that community health nurses can never assume that people will seek their services, or that governments will give them health care dollars merely because prevention has been identified as the key to better health. These authors encouraged community health nurses to employ effective political strategies to lobby for prevention and the expansion of their roles within the health care system. Such politicization is achieved by networking with other nursing and health care practitioners, community and government involvement in policy making, and educating the public and the policy makers (Larsen \& Baumgart, 1988; Matuk \& Horsburgh, 1989). With direct links to both the public and the government, community health nurses are in a key position to inform the public of who they are and what they do, and the value of their services. As a result, community health nurses are in an excellent position to have input into and direct future preventive care.

Participants in this study recognized the limitations and the need for future community health nursing programs:

With health promotion, there's so much more that could be done [but] with limited resources, limited funding, limited staffing, you certainly can't go about implementing more programs or promoting yourselves too much because you don't have the staff to offer the service. Each individual nurse...is not being underutilized...the whole service is being 
underutilized...the community probably could use a lot more of the type of services that the health department could and would like to offer.

Participants viewed visibility and value as linked to future demands for community health nursing services by clients and by governments. If community health nursing activities became visible and valued for their costeffectiveness and preventive focus, participants believed that there would be a demand by the public for maintenance and expansion of community health nursing services and programs. In essence, then, participants perceived that their expertise remained an untapped potential within the Canadian health care system.

\section{Subtheme Two: Research}

In order to facilitate the effective realization of present and future community health nursing roles and activities, participants recognized the value of relevant research. Most of the participants admitted to little knowledge or experience in conducting research. Nevertheless they valued appropriate research as an effective way to support the merits of present activities, illuminate the potential of future activities, and help to direct community health nursing practice:

I think it's important to direct and influence our practice...there comes a time either in something we've been doing for a long time or something that maybe we're not involved in at all that we need to be shown ourselves and the public as well that certain work is important and does make a difference...you need certain things to back up what you're doing...to substantiate it. Research can be innovative or a little bit different or there are ways of doing qualitative stuff versus just numbers all the time.

As a consequence of the value placed upon it by participants, research emerged as the second subtheme within theme five: Community health nurses value 
research because they believe it will demonstrate the value of community health nursing for present and future community health nursing endeavors.

Participants valued research as a process that contributes to the evaluation of present practice, as well as to the determination of future practice. They realized that research could help them determine if change was required in their practice, and if so, the type of change necessary to meet health care needs. Research could also illuminate the utility of community health nursing and help community health nurses to priorize care:

Good research is going to give us more up to date information on what's going on out there and what the needs are, and where we need to spend more of our energies.

In addition, participants valued research as a way to justify to themselves that the work they were doing did indeed make a difference. Participants wanted this justification because the outcomes of their activities are so often long term. In addition, outcomes are difficult to observe and measure to determine if nursing intervention made a (or the) difference. Participants believed that various research methods could clarify and demonstrate the utility of community health nursing to others:

...we're always saying, yes, I think this is important, I think we're making a difference here, I think people that come get something from it, but there's nothing really there to substantiate it. Research can be innovative or a little bit different or there are ways of doing qualitative stuff versus just numbers all the time...you need certain things to back up what you're doing...[to] show in a more concrete sort of way that the work is valuable which will help us and also show it to the wider public, that the work does make a difference...

Matuk and Horsburgh (1989) have noted the need for community health nurses in Canada to enhance role clarity and to promote the value of these roles to governments and the public. Goeppinger (1988) has suggested that 
research has the potential to determine, measure, and communicate the value of community health nursing roles and activities. However, Goeppinger (1988) also noted that certain challenges compromise much of community-oriented nursing research.

The first of these challenges relates to domain ambiguity - who the client is specifically, particularly when client is considered to be community, and identification of the practice roles for the various client foci. These considerations have implications for focusing and delimiting the boundaries of research activities (Oda \& Boyd, 1987). For example, it is difficult to clarify roles when these roles may vary markedly within various communities; this is compounded by the fact that community is variously considered as the public or ultimate beneficiary of practice, a unit of practice or intervention partner with whom the nurse interacts, the target of change, and a practice setting (Goeppinger, 1988). As participants noted, their roles and activities varied according to the health care needs and participation of various communities:

People have different values downtown, their values are to survive on the street...we could teach them about AIDS and TB...with the Chinese population...it was promoting western health and also accepting the health care that they themselves used... with the Native Indians, you had to mix both. You had to let them continue with their own health beliefs, but you also had to interweave within their own beliefs and value system how you were going to work with them.

Indeed community health nursing roles evolve even as clients themselves evolve and change.

A second challenge relates to measurement problems (Goeppinger, 1988). Determining and measuring the outcomes of community nursing practice is difficult when its domain is ambiguous. For example, a community 
health nurse's geographical area of responsibility is not the only determinant of nursing practice. External factors that exist outside of the nurse's geographical territory, such as cultural and religious communities, must also be acknowledged in nursing care and evaluation of that care. In addition, change within communities is a result of a variety of factors such as the media and other city resources such as self-help groups and social service agencies. As a result of these and other factors, it is difficult to determine and measure community change, and then attribute that change to community health nursing intervention.

Participants were interested in research and some had assisted others in research projects. However, participants noted that they would need support from administration in terms of time and opportunities for research education and activities if they were to add this activity, however valuable, to their already busy schedules. In addition, some participants attributed a mystifying and almost intimidating quality to research. As one participant explained:

I think research needs to be de-mystified - I mean we are actually doing research every single day that we work because we are always figuring out a care plan, trying it, discarding the stuff that doesn't work, getting new ones, pulling in ideas from other people, trying different interventions. De-mystify it a lot. Encourage people that if you are looking for statistics, hire a statistician. Don't think that you need to know everything...

Although participants believed that quantitative research was valuable in community health nursing, they placed equal and sometimes greater emphasis on qualitative research methods. Participants valued qualitative methods for their ability to present possibilities and promote understanding of client - nurse situations and interactions: 
What I would like to see more of is more sort of descriptive stuff. More stuff that's just like, we observed 200 situations and we found this kind of variety and...this many approaches and we'd like to suggest these as possibilities or alternates in these kinds of situations, rather than [research] that is so tightly controlled.

Quantitative research was valued for information related to population demographics, morbidity and mortality data, and other large scale assessment and epidemiological information. However, quantitative research was not perceived as appropriate for certain types of evaluation for a variety of reasons. One of these reasons related to the difficulty in accessing and maintaining community client involvement throughout the quantitative research process. A second reason was that the interactive and nonquantitative nature of nursing interventions, such as the establishment of a trusting relationship, sensitivity to cultural values, and the nature of the outcomes themselves precluded quantitative measurement. Participants noted that client behaviour change that is long term, that may not be observable and measurable, and that may have qualitative meaning for the client and not quantitative meaning for the researcher did not lend itself to quantitative evaluation:

I'm struggling with it [quantitative vs. qualitative research] myself and I'm getting those questions from other people and from administration as well...I realize that numbers are still important to justify our time but I also think that we need to look at what happens with those people. I mean, if you get 50 people come and they all just come for 2 minutes and they're all aware of the health department, is that better than 10 who maybe get a lot more out of it?

The value of and challenges to these competing research methodologies are acknowledged in the literature. Communities as naturalistic settings pose considerable threat to researcher control. Social interaction, a vital attribute of communities, must be accounted for in the evaluation of nursing intervention 
effects. However, extensive social interactions may be labelled 'subject contamination' by the quantitative researcher (Goeppinger, 1988).

Many community health nursing researchers are shifting their philosophic orientations from quantitative to qualitative perspectives (Goeppinger, 1988; Streubert, 1991). Qualitative research can be used to generate important problems, give meaning to numeric data, and verify quantitative data, which remains more convincing to funding agencies (Goeppinger, 1988). The complementary contributions of description and measurement, qualitative and quantitative research strategies, are also being acknowledged (Goodwin \& Goodwin, 1984). Goodwin and Goodwin (1984) have concluded that many studies could be enhanced if a combined approach to research were taken. They have suggested that the use of both quantitative and qualitative research methods could achieve a comprehensive understanding of meaning, context, and procedure that could not be achieved by either research method alone. In addition, they have noted that using both methods assists in cross-validating the findings, checks for congruence, increases the information yield, and strengthens the external validity of the research results.

Uncertain research environments are also a challenge to communityoriented research (Goeppinger, 1988). These environments are uncertain and unpredictable largely due to funding cutbacks. Wavering support from nursing and medical colleagues who identify the focus of research, defend research designs, and compete for dwindling research support also contribute to this uncertainty (Goeppinger, 1988). 
Funding cutbacks are frequently dealt with by health department administration by cutting programs, such as those related to research, rather than personnel. Formal research positions and activities rarely exist within community health departments, and this holds true for the health department in which the study participants worked. This has implications for the initiation and implementation of research projects, and the utilization of research findings by community health nursing staff. Because community health agencies are faced with increasing need for cost containment strategies (Matuk \& Horsburgh, 1989), they may emphasize quantitative research approaches that demonstrate their value in numerical terms that funding agencies such as governments appreciate. These variables present challenges to the enactment and effectiveness of research activities, and to the type and quantity of research methods that are supported within various health departments.

Goeppinger (1988) identified a further challenge that relates to the dissemination of research findings. Dissemination challenges center on how to report findings to diverse audiences in the scientific, professional, and lay communities, and on translating findings into practice guidelines so that nurses can adopt findings into their practices. Participants in this study identified difficulties in accessing research findings due to the lack of accessability of journal articles that reported relevant findings, lack of time to read and adapt these findings to their practice, and the nature of some of the research findings themselves:

Part of it is designing research so that it is valid as research...You have to follow all these tight controls and so on [but] it doesn't answer the big question. It might be very specific and say that there are 20 clients and 10 were looked at this way and 10 were looked at that way - so it is very 
reliable and valid. But I can read it and I can say that's very nice but it isn't broad enough because it is so finite and so carefully prescribed...like if you had something similar but not quite the same, then is that going to help you out?

Part of the problem in disseminating research findings then, may be due to the relevance of those findings, and constraints, such as time, in practice settings. However, participants did think appropriate research findings should be disseminated among themselves, as well as to the Canadian public and governments:

One paper I did in particular when I was with the province was on hand, foot, and mouth disease. We wrote it up and had all the statistics and everything and somehow it came into the hands of the newspaper in the small community that I was at. And they published it...Holy mackerel! People were really interested in that They wanted more information, stuff like that. It was really neat.

In summary, this chapter has presented and discussed the five central themes and accompanying subthemes that emerged from the data of this study as representing the value of community health nursing. These themes and subthemes were presented with reference to participants' perceptions, and discussed within the contexts of values clarification theory and other relevant literature sources. Although each theme was presented and discussed individually, it must be noted that these themes and subthemes form an interconnected web that holistically describes the value of community health nursing from participants' perspectives. Chapter five will address implications and conclusions for community health nursing that arise from the findings of this study. 
CHAPTER 5: SUMMARY, CONCLUSIONS, AND IMPLICATIONS

\section{Summary of the Study}

Because no literature was found that discussed community health nurses' values in relation to community health nursing, the purpose of this study was to explore and describe the value of community health nursing from the perspective of community health nurses. The study provided these nurses with an opportunity to articulate the value of community health nursing. Community health nurses who had direct involvement in preventive community health nursing practice were selected as research participants.

Values clarification theory (Steele \& Harmon, 1983) guided the conceptualization of the study. Values clarification is a process whereby an individual first chooses values, then prizes these values, and then acts upon these values. This is a dynamic process that is affected by life experiences, education, and many other factors. Values form the basis for decision-making and action-taking. Therefore, values clarification theory provided an appropriate framework for examining the values held by community health nurses, and the implications of these values for their decisions and actions.

The phenomenological method guided the research approach of the study. The purpose of phenomenology is to describe lived experience from the perspective of individuals who live that experience (Oiler, 1986). Phenomenology is an appropriate method to use in initial investigations and descriptions of a phenomenon, such as this study's description of the value of community health nursing. In addition, the focus of phenomenology is on the 
subjective reality of the participants, rather than on the a priori perspectives of the researcher. Therefore, phenomenology was appropriate in accessing the value of community health nursing from the perspectives of community health nurses.

Using the phenomenological method described by Colaizzi (1978), the researcher selected community health nurses from four metropolitan health units as study participants. From the community health nurses who expressed interest in participating, the researcher used non-probability sampling to select eleven community health nurses to participate in the study. These participants all held baccalaureate degrees in nursing, and had been working full-time for the past two years in community health nursing. In addition, they were all able and willing to honestly and openly articulate the value of community health nursing.

The eleven participants were each interviewed twice by the researcher in an effort to achieve clear and comprehensive insight into the value of community health nursing from their perspectives. The researcher was rigorously attentive to issues of reliability and validity throughout the data collection and data analysis periods of the study. Interviews were taped and transcribed verbatim. The researcher analyzed each transcript prior to the next interview so as to achieve understanding, identify themes, and determine data saturation. From the analyses of these twenty-two interviews, five themes emerged. These themes expressed the value of community health nursing in relation to activities, purposes, prerequisites for practice, visibility, and community health nursing as the way to the future in health care. The themes 
were organized into a description of the value of community health nursing, and this description was validated by three of the participants in third interviews as true to their perceptions of the value of community health nursing. The five themes were presented and discussed in relation to values clarification theory and other relevant literature.

\section{Conclusions}

The community health nurses in this study valued multiple and varied activities. The purpose of those activities was to enable and empower clients to make informed decisions, choices, and actions regarding health and health care within the context of the client. Client in community health nursing terms was described as an individual, family, group, or community. This client variation and the various activities that result from it were valued by community health nurses. Because community health nurses valued collaborative activities, the nature of those activities varied according to client characteristics such as capabilities, limitations, expectations, culture, and many other factors.

The community health nurses valued autonomy because it allowed them to be self-directing and to control decisions and actions necessary for effective practice - the what, where, when, how, and why of their client contact. Autonomy was also valued because it allowed community health nurses to priorize activities and make decisions about the effective and efficient allocation of resources. The community health nurses valued collegial and administrative acknowledgement of autonomous community health nursing practice. This acknowledgement contributed to feelings of job satisfaction. 
The community health nurses in this study also valued certain prerequisites in order to be effective and efficient in their practice. The first prerequisite was a broad knowledge base derived from nursing and public health knowledge, and from other disciplines such as the arts and humanities. They also valued informal knowledge, identified by participants as intuition, that is gained from practice experience. The community health nurses valued these types of knowledge for the understanding of humanity that they afforded, and for the support and direction this knowledge provided for the effective enactment of community health nursing activities.

A second prerequisite was that of certain personal qualities and attitudes. Participants valued certain personal attributes such as assertiveness, self-directedness, creativity, and respect for colleagues. They valued collegial and administrative support in facilitating the autonomy of their practice. They valued administrative input and support in terms of accessibility, expertise, and leadership. They also valued opportunities to benefit from each other's knowledge and experience because they functioned in isolation from other community health nurses in their day to day practice. Participants believed that nurses needed to have these prerequisites to practice effectively in community health nursing.

Community health nurses in this study valued community health nursing that was visible. They valued visibility because they believed it facilitated others' awareness and valuing of community health nursing services and their effective use of these services. The community health nurses in this study perceived that their activities were often not clearly or comprehensively 
perceived or visible to clients, the public, and sometimes even themselves. They felt that this lack of clarity contributed to role erosion and role fragmentation, and served to undermine awareness, valuing, and effective utilization of community health nursing services.

The community health nurses also valued political visibility because they believed it fostered government support for community health nursing services and programs. They viewed political involvement as a way to enhance their visibility and hence their value within government circles. Political involvement which enhanced visibility was seen as important because government agencies provide the majority of financial support for community health nursing programs and services.

Finally, the community health nurses valued community health nursing as the way to the future in health care. They valued the preventive focus and the cost-effectiveness of community health nursing as the bases for this future care. In addition, they believed research would demonstrate the value of community health nursing for present and future community health nursing endeavors. The community health nurses in this study expressed a lack of knowledge about various research methods and findings. However, they requested opportunities for learning about, participating in, and accessing findings from research projects. They were interested in becoming formally involved in research in the future.

\section{Implications}

The findings of this study have implications for community health nursing practice, administration, education, and research. Because of the 
interdependency of these four aspects of community health nursing, implications for each aspect have significance for and can impact upon each of the other aspects. The implications are discussed in terms of each of the four aspects of community health nursing in order to achieve clarity and understanding. However, the researcher invites the reader to also consider the implications in terms of their cumulative and interdependent effect on community health nursing as a whole.

Implications for Community Health Nursing Practice

The five themes of this study illustrate the value that community health nurses place on various aspects of their practice. In theme one, participants described valued activities that they indicated varied from traditional one-toone activities to the "new public health" that involves community development and group activities. Participants stated they valued a balance in the enactment of these various activities in order to be effective with different client populations, and to provide diversity and capitalize on their varied expertise within their practice.

This valuing of a balance in activities has implications for community health nursing as it is presently practiced in this metropolitan center. Three of the four health units emphasize the traditional one-to-one approach, while one health unit has moved to a predominantly group and community development approach in community health nursing practice. If community health nurses desire a more balanced approach and they are restricted from enacting this approach in their practices, they may become frustrated. 
For example, one participant described her frustration that resulted from a value inconsistency she experienced at her health unit. This participant valued more involvement in group and community development activities. She described her understanding of and connection with individual clients and their needs and capabilities, and the importance of transforming this knowledge and connection from an individual client base to the needs and abilities of groups and communities. This participant spoke about a continuum of care that originates in individual client empowerment and continues to the empowerment of groups and larger communities. She noted that the capabilities of a group lie in the capabilities of its members. However, she noted that time and opportunities for the development and enactment of group and community activities were not provided at the health unit where she works. As a result, this participant sometimes saw her values as not being consistent with the values of her health unit, and this contributed to her feelings of decreased effectiveness and frustration.

Conversely, another participant described the satisfaction she experienced from continued one to one interactions, as well as from group and community contacts, even though the primary focus of the health unit where she worked was on groups and communities. This participant believed that the value of community health nursing "exists in the opportunity for members of the public to have access to quite a lot of information and support all by calling the local health nurse". From this participant's perspective, client contact could be on an individual basis or on a group or community basis, and she has continued to incorporate all of these aspects into her practice. Furthermore, 
many participants discussed the importance of knowing individual community members as a way of gaining knowledge about the community as a whole, and as a way of connecting with community decision-makers and action-takers.

From participants' perceptions then, it would seem that the community health nurses in this study valued opportunities to utilize both approaches in their practice. The metropolitan health department studied must consider ways to provide opportunities for community health nurses to develop and enact both traditional and "new public health" approaches so as to effect quality care and retain satisfied and committed community health nursing practitioners.

Participants expressed a desire to participate, particularly during work hours, in discussions that would help to clarify community health nursing activities, and where they could also develop strategies to make these activities more visible. Such participation could help to more effectively actualize the expertise of community health nurses for present and future roles and activities, because experienced community health nurses could provide insight into the needs of clients and the potential of community health nursing involvement.

Participation in decisions about community health nursing activities could clarify values for community health nurses as a group. This type of values clarification could assist community health nurses to identify and subscribe to core community health nursing values in a cohesive and committed way. The identification of core group values would facilitate group cohesion, visibility, and power (Zerwekh, 1992), and this could decrease role 
erosion by other disciplines by making clear to them the purpose of community health nursing practice.

Collective community health nursing participation facilitates decisions regarding practice issues. Many participants discussed the value of collegial support and input in terms of such issues as client assessment and intervention. By reaching collective consensus about these and other practice issues, the practice of community health nursing can be facilitated.

Participants' value of participation in discussions that impact on their practice has implications for the opportunities that are available to community health nurses during work hours for such participation. Participants remarked that few formal opportunities existed during work hours for them to meet and reflect on their practice. Indeed, in reflecting on the value of community health nursing during the course of the research interviews, many participants wistfully stated that it would be helpful to have similar opportunities with their colleagues on a regular basis at work. While some participants did have time and opportunities for occasional informal contact with colleagues, many participants declared that this was hit and miss, or that they did not have sufficient time to engage in such contacts. Also, participants stated that they did not often engage in discussion to the depth that they did in the research interviews when they were interacting with colleagues informally.

Participants felt that formal acknowledgement and the provision of opportunities for collegial interaction by administration would help to legitimate such in depth discussions, and would also demonstrate appreciation for the value and challenges of community health nursing practice by administration. 
Accordingly, administration of the studied health department needs to consider ways to provide more time and opportunities for formal and informal community health nursing networking and interaction. Such interaction would strengthen autonomous community health nursing practice by providing support and input, and by helping to clarify and promote the value of community health nursing to community health nurses and others.

In addition to collegial input, participants also valued an adequate knowledge base in facilitating the autonomous enactment of their activities. In particular, as they moved into new areas of practice such as group and community development activities and in working with various cultures, participants consistently declared in this study their need for continuing education. As one participant explained, "...there's no one to pick up for you when you go out there...no one else is doing your job. You're the one that's responsible. All that assessment has to be done by you...you have to be aware of so many areas."

Therefore, a diverse and autonomous practice requires the provision of regular and relevant continuing education opportunities to facilitate an effective practice. Participants in this study suggested that workshops supported by the health department, up to date and relevant libraries at each health unit, tuition reimbursement for successful course completion, and paid time away from the workplace to attend relevant conferences would be some ways that would facilitate their access to continuing education. The health department in which participants were employed might incorporate these and other ways to provide continuing education opportunities to community health nurses. 
Participants also stated that although they valued their present activities, and valued community health nursing in terms of cost-effectiveness and quality of life issues, they were reluctant to promote these values because of unreliable government support. Participants realized that the electiondependent mandates of governments did not fit well with the long term nature of community health practice. This conflict in expectations fostered reluctance on the part of community health nurses to commit themselves to programs or services that would not be supported by various political regimes, or over the long term. As one participant explained, the termination by governments of successful community health nursing programs that have required much effort and time to develop and implement, contributed to an undermining of the credibility of community health nursing, and a sense of futility and frustration on the part of community health nurses.

An implication of this reluctance is that the visibility and value of community health nursing activities are not fully realized or are restricted. For example, some participants related how they were reluctant to be committed to new programs, such as those in community development proposals, or to develop new programs, such as those for various cultural groups, because of the historical lack of long term government commitment to community health nursing programs. This restricts the full and actualized practice of community health nursing and the effectiveness of the health care system. For example, community health nurses might develop and provide some services such as immunization and client education programs more effectively and inexpensively 
than other disciplines, such as physicians. This would potentially enhance the quality and decrease the cost of present health care delivery.

By utilizing community health nursing expertise that presently remains untapped, and by expanding the scope of community health nursing activities, unacknowledged and underutilized expertise becomes visible. Such full actualization of community health nursing potential also frees up other disciplines to be involved in activities that better utilize their expertise. This actualization could also contribute to a decrease in community health nursing role erosion by making clear the value of community health nursing. As community health nurses demonstrate their expertise, they could be inspired to expand into other areas of practice. Such success could create client demand for community health nursing services, and ensure more reliable support from funding bodies such as governments. A significant consequence of the full and effective realization of community health nursing potential could be a decrease in the costs of health care in British Columbia.

Participants stated that research that clearly illustrates the value of community health nursing was required to facilitate adequate and reliable funding for present and future community health nursing activities. In addition, participants believed that political involvement on the part of community health nurses would help to place their concerns and requirements on the government's agenda. However, participants admitted to a lack of knowledge and experience about the implementation of either of these techniques. They did express interest in learning more about research, politics, 
and political involvement so that they could support others or be actively involved in these activities.

Although many authors have discussed the importance of marketing as a way to make visible the value of community health nursing and to promote effective utilization and support for this practice, the participants in this study did not present this as a significant activity. Whether they did not see marketing as a value, or were simply unfamiliar with this technique is unclear. Because some participants alluded to marketing principles in broad terms, such as when they discussed the value of the role of the Community Health Nurses Group of the RNABC, the researcher believes that participants probably would value marketing strategies if they knew more about them.

Participants' unfamiliarity with strategies for research, political involvement, and marketing has implications for the practice of community health nursing. If community health nurses are unable to justify the value of their activities through research findings, they will be less able to access secure funding for the continuance of present programs, or for the development of future programs. In addition, a lack of proof of the value of their activities hinders their credibility and influence within the political environment. Also, lack of knowledge about the political environment and effective strategies to access and influence that environment contributes to a lack of effectiveness in achieving politically relevant goals. Finally, it is difficult to market community health nursing when one is unclear about what is to be marketed (as determined by research, and role clarification) or when one is unfamiliar with effective marketing strategies. 
From participants' perspectives, it is clear that effective marketing, research, and political involvement are required to alert the public to the existence and value of community health nursing services and programs. Community health nurses require support from formal and informal sources in order to acquire the necessary knowledge and skills in research, political involvement, and marketing. Support from formal sources such as the health department and community health nursing administrators could include educational opportunities to learn about research, the political environment within which the nurses work, and marketing strategies.

Additionally, community health nurses could be assisted to participate in appropriate activities related to these three areas. Some of these activities include participation in research projects and marketing strategies, and time to access and adapt research findings to particular practices. Participation in marketing of community health nursing services and programs will require political astuteness given that community health nurses are employees of the city, and the city where the study was located has variable commitment to community health nursing and preventive services.

Support from informal sources such as the provincial and national branches of the Community Health Nurses Group could include opportunities for participation of members in relevant research projects, presentation and discussion of research findings, education regarding research, marketing, and political activities, the development of marketing strategies, and lobbying activities directed at various levels of government. Participation in research, political, and marketing activities within these supportive environments can 
foster the full realization of effective community health nursing practice. These three areas of activity can achieve this by credibly identifying the value of community health nursing, by making this value more visible, and by actively and effectively seeking support for this value.

Stevens and Hall (1992) have stated that there is a lack of conceptual clarity about what constitutes nursing practice at the community level. Nevertheless, these authors have noted that the future of community health nursing depends on two things: (1) the recognition of social, economic, and political aspects of the environment as they affect health, and (2) interventions at the community level for structural change and empowerment. Participants in this study have described health in similar holistic terms, and they have recognized the importance of working not only with individuals but with the community as well.

Stevens and Hall (1992) have also recommended that community health nursing roles need to change from presenting solutions and directing lifestyle changes to asking critical questions that will assist communities in appropriate ways and times. Participants in this study have expressed interest in research that will facilitate community health nursing activities that enable and empower individuals, groups, and communities. Furthermore, participants have acknowledged the importance of working collaboratively with clients in identifying problems and reaching solutions.

Stevens and Hall (1992) have also noted that nurses are often constrained by a withdrawal of resources which undermines community trust and increases alienation on the part of disenfranchised aggregates. Participants 
in this study have also indicated their credibility is undermined when support is not assured. However, community health nurses alone cannot be expected to ensure viable and effective community health nursing practice. They require the assistance and support of others, particularly administrators. $\underline{\text { Implications for Community Health Nursing Administration }}$

Study participants valued opportunities for collegial and administrative "back up" and support. Participants stated that this support contributed to feelings of job satisfaction and commitment because the input from colleagues helped them to assess their values, decisions, and actions. Administrators then have a responsibility to provide opportunities for collegial and administrative input and support if they are to attract and retain satisfied and committed staff. Participants suggested that some of these opportunities might include time for both formal and informal collegial interaction, and an open door policy on the part of administrators so that community health nurses could access administrative expertise as required.

In addition, participants commented on the importance of being respected in administrative interactions as professionals with knowledge and expertise. Participants wanted administration to access their expertise and involve them in practice decisions. However, community health nurses also have a responsibility to make their expertise and their requirements known to administration.

As Steele and Harmon (1983) have noted, beneficial effects of collegial input and support include values clarification that promotes effective decisionmaking. Referent group values clarification may also help to facilitate 
clarification of present and future community health nursing roles and activities by identifying core group values. Furthermore, the identification of group values could facilitate the development of strategies by community health nurses to promote these values to themselves and others.

Zerwekh (1992) has suggested that the development of a community health nursing group identity and shared purpose will contribute to an increased professional visibility, decreased isolation, and increased sense of power for community health nurses. Participants remarked upon the isolation they often felt because they were the only nurses responsible for each of their communities. Group interaction helps to decrease feelings of isolation and affirms for nurses similar values and actions. These strategies, together with research and marketing of community health nursing value, could increase the valuing of community health nursing by clients and governments. One result could be that governments will become more committed to consistent funding for community health nursing programs and services. Opportunities for collegial and administrative interaction then could enhance community health nursing decision-making, and facilitate development of present and future roles and activities.

Participants also valued administrators for their ability to facilitate community health nursing roles and activities. In order to effectively facilitate these roles and activities, participants believed that administrators had to be knowledgeable about and appreciate community health nursing practice. They also expected their administrators to be effective leaders who were able to 
represent community health nursing interests and values to community health nurses, other disciplines, clients, and the government.

These expectations regarding administrative expertise imply that administrators must be well prepared in terms of experience and education. However, in Canada in 1986, only 7.1 percent of nursing directors and associate directors in community health held a graduate degree in nursing, and 31.8 percent had a baccalaureate degree (Matuk \& Horsburgh, 1989). In Canada in 1988, only 1 percent of community health nurses at any level of practice held a masters or higher degree; in British Columbia that same year, only 2 percent of community health nurses held masters or higher degrees (Chalmers \& Kristjanson, 1992). Given that community health nursing requires knowledge from a variety of disciplines, such as education, epidemiology, and public health, graduate education in other disciplines would also be valid for community health nursing administrators. Indeed, in the metropolitan area studied, the majority of community health nursing administrators hold graduate degrees in these other disciplines, rather than in nursing.

Matuk and Horsburgh (1989) have recommended that the availability and accessibility of baccalaureate and masters programs be increased, and that funding and flexible work schedules be made more available to facilitate upgrading. These recommendations would facilitate masters level education for the participants in this study since some participants indicated that they would be interested in pursuing masters education but could not do so either due to lack of funding or to lack of a flexible work schedule. In addition, because these participants were already experienced community health nurses who held 
baccalaureate degrees, opportunities for further education at the graduate level would help them become more effective leaders in community health nursing.

Participants in this study felt appreciated when they were given administrative positions or duties, such as when the administrator was on vacation or otherwise not avallable to the health unit. Participants recommended that positions be developed within the health department to acknowledge and utilize their expertise. Some of these positions could include clinical specialty and research roles. These roles would benefit the community health nurse in the position as well as other community health nurses to whom she could act as a consultant. In addition, as participants explained, these positions would contribute to job satisfaction, commitment, and retention of community health nurses who have much expertise within the health department. Indeed, Martin and McGuire (1990) found that opportunities for clinical advancement within a community health nursing agency resulted in the staff feeling a heightened sense of professionalism and financial reward for clinical ability. Participants in this study also acknowledged the importance of adequate financial remuneration for their expertise and some suggested that their expertise and knowledge were inadequately recognized and compensated.

In summary, participants valued administrators who would listen, hear them, respect them, and support them. Some participants used words similar to the following, "She heard me. I had a voice that was heard" when describing valued administrators. It is important to note that the perspectives described here are those of community health nurses, not of administrators. Administrators could potentially provide insight into the many factors and 
variables that enter into administrative practice and decision making. A study that accessed administrative perspectives would be an interesting complement to the staff perspectives offered here.

\section{Implications for Community Health Nursing Education}

Participants valued a broad knowledge base in order to be effective in their practice. They valued formal knowledge in nursing, public health, and the arts and humanities, as well as informal knowledge gained from experience. Participants valued these knowledge sources for their contributions to the understanding of people, so crucial to community health nursing practice.

The knowledge that participants valued has implications for nursing education. Various authors cited in this study have noted that nursing education is inadequate for and often irrelevant to the practice of community health nursing. Study participants also stated that community health nursing education seems inadequate based on their experiences of having nursing students in their health units.

Participants were particularly concerned about the small amount of time students spent in community health nursing settings, and their limited experiences. Participants wondered if these students would choose community health nursing after graduation based on their limited exposure and their lack of confidence in their knowledge and skills. Participants perceived that these students viewed nursing in terms of illness care in institutions involving high technology. In addition, participants felt that students valued nursing care more in terms of doing something to a patient, rather than consultative and collaborative care that is characteristic of community health nursing. 
Community health nursing content and experience are frequently not clearly articulated, or not articulated at all within nursing programs (Salmon, 1989). This has implications for the vision that students acquire about what it means to be a nurse and their future careers in nursing (Salmon, 1989; Deiman, Jones, \& Davis, 1988). Students in nursing programs may develop the view that "real" nursing occurs in institutions or in treatment oriented settings, and they may, therefore, not consider community health nursing as a valid career choice. In addition, students who choose to work in treatment settings following graduation may not appreciate or utilize community health nursing expertise, for example they may not initiate client referrals or other contacts with nurses in the community. Indeed, study participants stated they received few referrals or other contacts from hospital nurses. This has implications for the effective and efficient utilization of community health nursing services, and for quality health care. Therefore, the quality of community health nursing education has direct implications for nursing practice in all areas.

Concepts recommended as essential to baccalaureate preparation of community health nurses - such as the health of aggregates or concepts from disciplines other than nursing, both identified by participants as important for effective practice - are often not significantly represented in nursing education programs (Blank \& McElmurry, 1988; Kenyon et al., 1990). This is particularly evident in nursing programs that utilize nursing theories that focus predominantly on individuals rather than aggregates (Stevens \& Hall, 1992), and in programs that use an integrated curriculum (Chavigny \& Kroske, 1983). 
Professional practice should guide and direct educational curriculums. Stevens and Hall (1992) have asserted that a key to effective community health nursing practice is the interwoven process of critical reflection and action. This process demands that community health nurses must act in various ways including taking a stand with regards to their responsibilities to communities, asking critical questions, facilitating egalitarian dialogue, forming coalitions, and using collective strategies with communities and in participatory research. Yet nursing education programs do not usually use theoretical frameworks that prepare students to understand, appreciate, and use these processes and activities, so critical to community health nursing (Stevens \& Hall, 1992). Adequate and appropriate experience and time in community health nursing settings with guidance from qualified instructors are not provided for nursing students in many nursing programs (Deiman, Jones, \& Davis, 1986). Nursing education remains focused on acute care and acute care settings, a focus that negates the value of community health nursing and does a disservice to the preparation of effective community health nursing practitioners (Kenyon et al., 1990). Students do not acquire knowledge and skills for effective community health nursing practice, and, therefore, do not develop an appreciation for this challenging field.

Such nursing education has implications for the attraction and retention of effective community health nursing practitioners. Graduates of these nursing programs may not choose to enter the practice of community health nursing due to their lack of knowledge and experience with this field of nursing (Kenyon et al., 1990). Those graduates who do choose to enter community health 
nursing will be compromised in their abilities to effectively enact community health nursing roles and activities (Salmon, 1989). As a consequence, these nurses may become dissatisfied and leave community health nursing, and perhaps nursing altogether. Therefore, approprate community health nursing education is critical to the attraction and retention of effective community health nursing practitioners.

In these times of crisis when such issues as role clarity and erosion, the determination of future roles and activities, and financial constraints are at the forefront of community health nursing concerns, nursing education has an obligation to adequately educate students. These students must be prepared to take on these challenges and effectively, indeed proactively, contribute to this field of practice. In the United States, the Association of Community Health Nursing Educators have identified community health nursing education as a national priority (Riportella-Muller, Selby, Salmon, Quade, \& Legault, 1991). Many authors cited in this study have made recommendations regarding the nature and placement of community health nursing education within baccalaureate and graduate nursing education programs. Their recommendations are remarkably similar to participants' suggestions for knowledge they deemed essential to their practice. The issue is not what needs to be taught. Rather the issue is a lack of valuing of and commitment to community health nursing education by faculty within nursing education programs (Salmon, 1989; Salmon, Riportella-Muller, \& Selby, 1991). Various external and internal forces influence nursing faculty and programs with 
respect to the community health nursing content and experiences that are included in nursing education programs (Salmon et al., 1991).

External forces from the nursing profession are of primary significance. Community health nursing has not been a mainstream part of nursing's agenda for a number of years (Salmon, 1989; Salmon et al., 1991). Indeed, participants in this study stated that they did not feel significantly valued within the nursing profession. Only recently with the development of the Community Health Nurses Group did they feel that they had an impact and were an important and acknowledged part of their professional body, the Registered Nurses Association of British Columbia.

As a consequence of this undervaluing of community health nursing by the profession, various changes have occurred within nursing education (Salmon et al., 1991). Accreditation demands and licensing examinations have tended to focus on acute care priorities. Consequently, nursing education programs have integrated relevant concepts into overall nursing curricula so as to provide more opportunity for the provision of acute nursing knowledge. This has created a climate in which community health nursing has become barely, if at all, identifiable within nursing education programs (Salmon, 1989).

The market is another external force that shapes the character of nursing education programs (Salmon et al., 1991). The relative invisibility of community health nursing within the practice world of nursing, as presented by the media and within nursing education programs, does not create a demand by students for this type of education. However, given the idealism, social concern, and activism frequently found in undergraduate students, and 
with the use of role models and other real life practice settings, community health nursing can be taught in exciting and challenging ways (Salmon et al., 1991).

The key internal forces for education include the essential commitment to change and the support and resources to effect that change (Salmon et al., 1991). Salmon (1989) has declared, "For many years, public health nursing faculty have fought their battles for survival in relative isolation. They have been among the least well supported and understood of any nursing faculty" (p. 72). However, these faculty are in the best position to answer the call for activism and change in community health nursing education.

By virtue of "being there" within nursing education programs and the resultant opportunities to network with other nurses and educators, these nurse-educators are in key positions to have an impact on professional associations and nursing education departments. Salmon et al. (1991) have suggested that these faculty serve on accreditation and licensing boards so as to get community health nursing issues on their agendas. Participation on the part of these educators on task forces and ad hoc committees to look at what is required to address the critical deficits in community health nursing education are other avenues for activism. By the nature of the power of their positions and professional status, these educators can enlighten others through professional networks and contacts, writing activities, and public speaking.

These nurse-educators have a special responsibility for initiating and implementing change in nursing education programs. However, due to their decreased numbers and impact within nursing programs, these educators will 
need the support of their colleagues in the nursing profession, in other specialties, and outside nursing (Salmon et al., 1991). Through their help, it is more likely that education programs will seriously address the question of what is being done to address the pressing need for well prepared community health nurses.

Salmon et al. (1991) have declared that the time to act is now because a window of opportunity has been created by a society that is becoming acutely aware of its health and social problems. In addition, the present British Columbian government's commitment to the implementation of the Royal Commission's (1991) recommendations for more and improved community and preventive services has created unprecedented opportunities for community health nursing. Nursing education has a special responsibility to prepare community health nurses who can seize these opportunities. If nursing education programs do not fulfil their obligation to adequately educate students, the future of community health nursing practice is placed at risk. Salmon (1989) has stated, "The primary forces shaping educational content are the values and assumptions on which it is based. These values and assumptions constitute the pervasive and frequently unconscious culture that directs all aspects of an organization and determines its membership...differing values shape how practitioners are taught and rewarded; they also shape the 'vision' educators instill in students regarding their future careers" (p. 226). Nursing education has an obligation to promote in its students a vision of community health nursing that is based on a clear and accurate understanding 
of and appreciation for the value of community health nursing. Otherwise, the practice of community health nursing may become obsolete. Implications for Community Health Nursing Research

Participants in this study valued research for its ability to clarify, evaluate and direct community health nursing practice, provide data for policy decisions, illustrate community health nursing's value to themselves and others, and provide evidence of community health nursing's value to funding agencies such as governments. Participants valued opportunities to participate in research projects. They noted the value of both quantitative and qualitative research methods, although they seemed to prefer the qualitative results as being more directly applicable to their practice. Participants perceived a lack of research relevant to community health nursing, and they recommended that more community health nursing research be done. They suggested that more research could be done in their work places if it were supported more by administration, and if community health nurses were given opportunities and time to learn about and participate in research activities.

In view of these findings, several suggestions are offered. Nursing educators and nursing administrators might provide opportunities for nursing students and community health nurses to learn about and participate in community health nursing research. Some of the participants in this study stated that they would welcome such opportunities if they were given the time to be involved. Experienced community health nurses could help to identify the type of knowledge required and the research methods that would best access this knowledge. For example, one participant had attended a conference where 
participatory research was discussed and, as a result, was very interested in this method. This participant saw this method as a useful way to access client issues, and to motivate client participation in problem solving. This participant was so enthused about participatory research that she later sent the researcher references and information about it.

Community health nurses' interest in research activities could be utilized in a number of ways. Community health nurses could help to direct research that evaluates outcomes of current practice. For example, one participant spoke about the way that health fairs organized by community health nurses are evaluated. This participant noted the merit in determining qualitative value of these fairs to clients who attended, as well as quantitative value in terms of the numbers of clients who attended. As this participant queried, "If you get 50 people come and they all just come for 2 minutes and they're all aware of the health department, is that better than 10 who maybe get a lot more out of it?"

Community health nurses have direct and familiar contact with clients who may participate in research studies. This contact could facilitate research activities in ways that an "outsider" could not achieve. One participant discussed a study that was done in her area by a medical student. The participant noted that the medical student failed in his research attempt because he couldn't get people to talk to him. The participant believed that the people would have talked to her because they knew and trusted her. She offered to assist with or even perform the data gathering sections of the study, since she had assisted with the identification of the original research question, but the health department would not allow her the time to do this. The 
participant believed this lack of support from the health department was due to lack of funds and a lack of administrative support for the participant's involvement. This event suggests that consideration of the resources set aside by the health department for community health nursing research and for community health nursing participation in research is required.

This participant's experience also points out the significance of administrative support for research activities by staff. If administration has not valued or facilitated research activities by staff within the health units, then this activity did not and will not occur. Furthermore, participation by community health nurses in research projects may result in a commitment to use research findings in practice settings. This can only strengthen community health nursing practice.

Research that clarifies community health nursing roles and activities and their importance in present and future health care is needed. For example future research questions could include: (1) What are the effects of the withdrawal of community health nursing services? (2) How can present community health nursing services and programs be more effectively and efficiently implemented? (3) What future roles and activities do you see as valuable for community health nurses and why? and (4) What is needed to facilitate the development and implementation of future community health nursing roles and activities?

These and other essential questions could be addressed in a variety of ways. Each question could form the basis for a single research study in order to access a large amount of detailed data about one aspect of community 
health nursing, or various aspects of each question could be incorporated into a major study in order to acquire an overall picture of the status of community health nursing. In addition, research questions could be addressed using quantitative questionnaire or survey types of research methods to acquire data that is of particular value to governments and administration. Qualitative approaches could also be used and participants could be involved in a more open ended and direct fashion to acquire understanding from participants' perspectives.

Research questions are important to ask not only of community health nurses in a particular city, but also of a larger population of community health nurses. This research study accessed the perceptions of community health nurses in a major metropolitan center. However, the perceptions of community health nurses in other areas of British Columbia and of Canada could also be accessed, for example in rural areas and in other provinces and cities. Information from these sources would provide a more comprehensive understanding of the value of community health nursing from a Canadian perspective.

The perspectives of clients and colleagues could also be accessed. Since virtually no surveys of consumer perceptions and expectations of preventive community health nursing services have been done in Canada (Matuk \& Horsburgh, 1989), research questions would be appropriate to ask of clients who live in a variety of settings. The perceptions of community health nursing administrators, educators, and researchers could also be accessed because of their significant influences on community health nursing knowledge and 
practice. Also, it would be insightful to survey the perceptions of colleagues in other disciplines such as teaching, social work, psychology, and medicine. Perceptions about community health nursing roles and activities by these colleagues could provide knowledge about the image of community health nursing. This knowledge would help community health nurses focus and develop roles and activities, and relevant marketing activities.

Zerwekh (1992) has suggested that the lack of a community health nursing group identity and shared purpose have contributed to increasing professional invisibility, isolation, estrangement from one another, and powerlessness. As a result, the real and potential value of community health nursing practice remains unappreciated, underutilized, or inappropriately effected, thereby placing community health nurses as a population at risk (Zerwekh, 1992). This research study and the research proposed above will help to foster a community health nursing group identity by identifying common values, purposes and goals. These can then form the bases for concerted and effective community health nursing practice.

Research inquiry could also explore other factors that are or could be associated with the value of community health nursing. For example, the requirements for effective community health nursing administrators and the impact of these requirements on community health nursing practice, job satisfaction, and the recruitment and retention of community health nurses, would be significant areas to explore. Research could also be undertaken to determine the appropriate requirements of community health nursing education and its implementation within baccalaureate programs. Participants 
and authors cited in this study revealed the important roles nursing administration and education have to play in the continuance and advancement of this field of nursing. Although some literature that addresses factors related to community health nursing education and administration is available, a Canadian perspective is not clearly articulated.

Further research could explore other areas that impact on the value of community health nursing. Because community health nurses are predominantly women, research that explores the relationship between the psychology of women, particularly as this relates to feminist theories, and the value of community health nursing could provide insight. Although women's psychology and its impact on community health nursing did not emerge as a theme of this study, various participants did refer to this factor in their discussions.

Furthermore, research that investigates the various roles that community health nurses play as women, for example as mothers and partners in relationships, and the effect of these roles on job and career commitment would be useful. Some participants in this study indicated that responsibilities to families inhibited their ability to be involved in community health nursing activities after work hours. This lack of avallability has implications for the involvement of expert community health nurses in networking and the proactive enhancement of community health nursing practice.

This research addressed a broad area of study, the value of community health nursing. In building upon the findings of this study, future research could take a narrower perspective and investigate in more depth one or more of 
the findings of this study. For example, research questions could include: (1) What is the value of home visits? What is the value of community development? How can these activities both be incorporated in community health nursing practice? (2) How can community health nursing visibility be enhanced? (3) How can the potential of community health nursing be effectively accessed for present and future community health nursing endeavors? Perspectives from community health nurses, clients, and colleagues regarding these and other questions could help to clarify roles and assist in the development of strategies for marketing and political involvement.

In summary, this study provides a beginning description of the value of community health nursing from the perspective of community health nurses. More study is required to clearly articulate the importance of this field of nursing, particularly from the Canadian perspective. If health care in this country is to move forward in an effective and efficient manner, community health nursing must be included in that move. By describing the value of community health nursing from the perspective of community health nurses in a large urban environment, this study offers a beginning direction for community health nursing practice, administration, education, and research to move into the future. 


\section{REFERENCES}

Archer, S. (1983). Marketing public health nursing services. Nursing Outlook, 31(6), 304-309.

Barkauskas, V. (1982). Public health nursing practice - an educator's view. Nursing Outlook, 30(4), 384-389.

Barkauskas, V. (1983). Effectiveness of public health nurse home visits to primarous mothers and their infants. American Journal of Public Health, 73(5), 573-579.

Baum, F. (1990). The new public health: Force for change or reaction? Health Promotion International, $\underline{5}(2), 145-150$.

Bell, J., \& Wright, L. (1990). Flaws in family nursing education. The Canadian Nurse, $\underline{86}(6), 28-30$.

Blank, J., \& McElmurry, B. (1988). A paradigm for baccalaureate public health nursing education. Public Health Nursing, $\underline{5}(3), 153-159$.

British Columbia Royal Commission on Health Care and Costs. (1991). Closer to home: Summary of the report of the BC Royal Commission on health care and costs. Victoria, BC: Crown Publications.

Brown, L. (1991). Nursing research: The practice connection. Nursing BC, 23(3), 27-30.

Canadian Public Health Association. (1990). Community health - public health nursing in Canada: Preparation and practice. Ottawa: Canadian Public Health Association.

Chalmers, K., \& Kristjanson, L. (1992). Community health nursing practice. In A. Baumgart \& J. Larsen (Eds.), Canadian nursing faces the future (2nd ed.) (pp. 153-177). Toronto: Mosby Yearbook.

Chavigny, K., \& Kroske, M. (1983). Public health nursing in crisis. Nursing Outlook, $\underline{31}(6), 312-316$.

Clarke, H., Beddome, G., \& Whyte, N. (1990). Vision for tomorrow: A public health nursing driven future for public health nursing. Vancouver: Registered Nurses Association of British Columbia.

Colaizzi, P. (1978). Psychological research as the phenomenologist views it. In R.Valle \& M. King (Eds.), Existential - phenomenological alternatives for psychology (pp.48-71). New York: Oxford University Press. 
Deiman, P., Jones, D., \& Davis, J. (1988). BSN education and PHN practice: Good fit or mismatch? Nursing Outlook, 36(5), 231-233.

De Silva, P. (1988). Public health nursing: Phenomenologic meaning and dialectical theory. Unpublished doctoral dissertation, University of Texas, Austin.

Dye-White, E. (1984). Public health nursing: A crisis in definition, role, and function. Home Healthcare Nurse, 2 (5), 12, 14.

Elfert, H., \& Anderson, J. (1987). More than just luck. The Canadian Nurse, $\underline{8}(4), 14-17$.

Epp, J. (1986). Achieving health for all: A framework for health promotion. Ottawa: Ministry of Supply and Services.

Ervin, N. (1982). Public health nursing practice - an administrator's view. Nursing Outlook, 30(4), 390-394.

Field, P., \& Morse, J. (1985). Nursing research: The application of qualitative approaches. Rockville, Maryland: Aspen.

Goeppinger, J. (1988). Challenges in assessing the impact of nursing service: A community perspective. Public Health Nursing, $\underline{5}(4), 241-245$.

Goodwin, L., \& Goodwin, W. (1984). Qualitative vs. quantitative research or qualitative and quantitative research? Nursing research, $\underline{33(6), 378-380 .}$

Gulino, C., \& LaMonica, G. (1986). Public health nursing: A study of role implementation. Public Health Nursing, $\underline{3}(2), 80-91$.

Hernandez, S., Kaluzny, A., Parker, B., Chae, Y., \& Brewington, J. (1988). Enhancing nursing productivity: A social psychologic perspective. Public Health Nursing, $\underline{5}(1), 52-63$.

Hutchinson, S. (1986). Grounded theory: The method. In P. Munhall \& C. Oiler (Eds.), Nursing research: A qualitative perspective (pp. 111-130). Norwalk, Conn.: Appleton-Century-Crofts.

Jansen, J. (1990). B.C.'s health care future: Why a royal commission? In Registered Nurses Association of British Columbia [RNABC], Tell the Royal Commission on health care and costs a thing or two: Suggestions for preparing minibriefs (pp. 9). Vancouver: RNABC.

Jarvis, L. (1985). Community health nursing. In L. Jarvis (Ed.), Community health nursing: Keeping the public healthy (2nd ed.) (pp. 3-15). Philadelphia, PA: F.A.Davis. 
Jenny, J. (1990). Self-esteem: A problem for nurses. The Canadian Nurse, 86(10), 19-21.

Jones, P., \& Craig, D. (1988). Nursing practice in the community: Primary health care. In A. Baumgart \& J. Larsen (Eds.), Canadian nursing faces the future: Development and change (pp. 135-149). Toronto: C.V. Mosby.

Josten, L. (1989). Wanted: Leaders for public health. Nursing Outlook, 37(5), 230-232.

Kalisch, P., \& Kalisch, B. (1984). The press Image of community health nurses. Public Health Nursing, 1(1), 3-15.

Kenyon, V., Smith, E., Hefty, L., Bell, M., McNeil, J., \& Martaus, T. (1990). Clinical competencies for community health nursing. Public Health Nursing, $\underline{7}(1), 33-39$.

Laffrey, S., Renwanz-Boyle, A., Slagle, R., Guthmiller, A., \& Carter, B. (1990). Elderly clients' perceptions of public health nursing care. Public Health Nursing, $\underline{7}(2), 111-117$.

Labonte, R. (1989). Community and professional empowerment. Canadian Nurse, 85(3), 23-28.

Lalonde, M. (1974). A new perspective on the health of Canadians. Ottawa: Information Canada.

Larsen, J., \& Baumgart, A. (1988). Overview: Use of the political process. In A. Baumgart and J. Larsen (Eds.), Canadian nursing faces the future: Development and change (pp. 383-398). Toronto: C.V. Mosby.

Lucas, M., McCreight, L., Watkins, J., \& Long, S. (1988). Job satisfaction assessment of public health nurses. Public Health Nursing, 5(4), 230234.

Maglacas, A. (1988). Health for all: Nursing's role. Nursing Outlook, $\underline{36}(2), 66-$ 71.

Martin, E., White, J., \& Hansen, M. (1989). Preparing students to shape health policy. Nursing Outlook, 37(2), 89-93.

Martin, S., \& McGuire, M. (1990). A clinical ladder for the community healthcare setting. Journal of Community Health Nursing, Z(4), 189-197.

Mason, D., \& Talbott, S. (1985). Political action handbook for nurses: Changing the workplace, government, organizations, and community. Menlo Park: Addison-Wesley. 
Matuk, L., \& Horsburgh, M. (1989). Rebuilding public health nursing practice: A Canadian perspective. Public Health Nursing, 6(4), 169-173.

McCreight, L. (1989). The future of public health. Nursing Outlook, 37(5), 219 225.

Morse, J. (1986). Quantitative and qualitative research: Issues in sampling. In P. L. Chinn (Ed.), Nursing research methodology (pp. 181-193). Rockwell, Maryland: Aspen Publications

Munhall, P., \& Oiler, C. (1986). Philosophical foundations of qualitative research. In P. Munhall \& C. Oiler (Eds.), Nursing research: A qualitative perspective (pp.47-63). Norwalk, Conn.: Appleton-CenturyCrofts.

Natanson, M. (1973). Edmund Husserl: Philosophies of infinite tasks. Evanston, Illinois: Northwestern University Press.

Neylan, M. (1991). Assessing values. Nursing BC, 23(1), 5.

Oda, D. (1989). Home visits: Effective or obsolete nursing practice? Nursing Research, 38(2), 121-123.

Oda, D., \& Boyd, P. (1987). Documenting the effect and cost of public health nursing field services. Public Health Nursing, $\underline{4}(3), 180-182$.

Oiler, C. (1986). Phenomenology: The method. In P. Munhall \& C. Oiler (Eds.), Nursing research: A qualitative perspective (pp. 69-84). Norwalk, Conn.: Appleton-Century-Crofts.

Omery, A. (1983). Phenomenology: A method for nursing research. Advances in Nursing Science, $\underline{5}(2), 49-63$.

Orem, D. (1985). Nursing: Concepts of practice (3rd ed.). New York: McGrawHill.

Pender, A. (1987a). Economic incentives for prevention and health promotion. In N. Pender, Health promotion in nursing practice (2nd ed.) (pp. 445458). Norwalk, Conn.: Appleton \& Lange.

Pender, N. (1987b). Toward a definition of health. In N. Pender, Health promotion in nursing practice (2nd ed.) (pp. 15-36). Norwalk, Conn.: Appleton and Lange.

Pender, N. (1987c). Settings for health promotion. In N. Pender, Health promotion in nursing practice (2nd ed.) (pp. 75-92). Norwalk, Conn.: Appleton \& Lange. 
Rachlis, M., \& Kushner, C. (1989). Second opinion: What's wrong with Canada's health care system and how to fix it. Toronto: Harper \& Collins.

Rankin, J., \& Leversage, J. (1991). Leading the way. The Canadian Nurse, 87(2), 21-23.

Raths, L., Harmin, M., \& Simon, S. (1966). Values and teaching: Working with values in the classroom. Columbus, Ohio: Chas. E. Merrill.

Registered Nurses Association of British Columbia, (1992a). Determinants of health: Empowering strategies for nursing practice. Vancouver: RNABC.

Registered Nurses Association of British Columbia. (1992b). Dialogue on new directions. Vancouver: RNABC.

Riordan, J. (1991). Prestige: Key to job satisfaction for community health nurses. Public Health Nursing, $8(1), 59-64$.

Riportella-Muller, R., Selby, M., Salmon, M., Quade, D., \& Legault, C. (1991). Specialty roles in community health nursing: A national survey of educational needs. Public Health Nursing, $\underline{8}(2), 81-89$.

Rokeach, M. (1973). The nature of human values. New York: Free Press.

Salmon, M. (1989). Public health nursing: The neglected specialty. Nursing Outlook, 37(5), 226-229.

Salmon, M., Riportella-Muller, R., \& Selby, M. (1991). Public health nursing education: A call for action. Public Health Nursing, $\underline{8}(2), 68-73$.

Sandelowski, M. (1986). The problem of rigor in qualitative research. Advances in Nursing Science, $\underline{8}(3), 27-37$.

Shamansky, S., \& Pesznecker, B. (1981). A community is... Nursing Outlook, $\underline{29}(3), 182-185$.

Simon, S., \& Kirschenbaum, H. (1972). Values clarification: A handbook of practical strategies for teachers and students. New York: Hart Publishing.

Steele, S., \& Harmon, V. (1983). Values clarification in nursing (2nd ed.) Norwalk, Conn.: Appleton-Century-Crofts.

Stevens, P., \& Hall, J. (1992). Applying critical theories to nursing in communities. Public Health Nursing, $\underline{9}(1), 2-9$. 
Sullivan, J. (1984). Charge for the future. In J. Sullivan (Ed.), Directions in community health nursing (pp. 349-351). Oxford: Blackwell Scientific Publications.

Sullivan, J. (1984). Overview of community health nursing research and evaluation. In J. Sullivan (Ed.), Directions in community health nursing (pp. 175-206). Oxford: Blackwell Scientific Publications.

Tansey, E., \& Lentz, J. (1988). Generalists in a specialized profession. Nursing Outlook, $\underline{36}(4), 174-178$.

Tinkham, C., Voorhies, E., \& McCarthy, N. (1984). Community health nursing: Evolution and process in the family and community (3rd ed.). Norwalk, Conn.: Appleton-Century-Crofts.

Uustal, D. (1977). The use of values clarification in nursing practice. The Journal of Continuing Education in Nursing, 8 (3), 8-13.

Webster's new collegiate dictionary. (1979). Toronto: Thomas Allen \& Son.

Wells, B. (1991). Andrea Henning: BC's new provincial nurse advisor. Nursing BC, 23(3), 18-19.

Williams, C. (1977). Community health nursing - what is it? Nursing Outlook, $\underline{25}(4), 250-254$.

Williams, C. (1981). Nursing leadership in community health: A neglected issue. In J. McCloskey \& H. Grace (Eds.), Current issues in nursing. Boston: Blackwell Scientific Publications.

World Health Organization, Health \& Welfare Canada, \& Canadian Public Health Association. (1986). Ottawa charter for health promotion. Ottawa: Canadian Public Health Association.

Zerwekh, J. (1992). Community health nurses - A population at risk. Public Health Nursing, $\underline{9}(1), 1$. 


\section{APPENDICES}




\section{Appendix A}

\section{Information Letter to Community Health Nurses}

My name is Beverly Leipert. I am a registered nurse enroled in the Master of Science in Nursing program at the University of British Columbia. From my work as a community health nurse, I have become interested in the perceptions of other community health nurses regarding the value of community health nursing. For my thesis I am conducting a study to learn about these perceptions of community health nurses. The title of my study is "The Value of Community Health Nursing: A Phenomenological Study of the Perceptions of Community Health Nurses".

Community health nurses with two years of recent prevention experience and a baccalaureate degree in nursing are invited to participate in this study. As a participant, you will be interviewed about your perceptions about the value of community health nursing. You will be free to decline to answer any of the questions I ask during the interview, and you will be encouraged to add your own perspectives to the interview. There are no risks to participants in this study. However, participation in this study may provide personal and professional benefits. Personally, your participation may assist you to clarify some of your own values about community health nursing. Professionally, your participation will assist others to understand the perceptions of community health nurses.

Participation in the study will involve two and possibly three interviews. One hour will be scheduled for each interview. These interviews will be conducted face-to-face and will be scheduled at a mutually convenient time either in your residence or at the Health Unit. The interviews will be audiotaped and transcribed to help me recall and analyze the information that has been shared. The audiotapes and transcriptions will be stored in a secure manner in my home, and they will be erased upon the completion of all scholarly work.

Confidentiality is assured. Any names or other identifying information will be omitted from the transcripts. You are under no obligation to participate in this study. If you do decide to participate, you are free to withdraw at any time. Withdrawal from the study will not result in any personal or professional repercussions.

If you are interested in learning more about this study or in participating, please feel free to call me at 876-2803. I will answer your questions and, if you are interested in participating in the study, we will arrange a mutually convenient time to meet. When we meet to initiate the first interview, I will obtain a written consent from you prior to the interview and taping. I thank you for your interest in my study, and I look forward to your participation.

Sincerely,

Beverly Leipert R.N., B.A., B.S.N.

Phone: 876-2803 
Appendix B

\section{Consent to Participate}

I hereby give my consent to participate in the study, "The Value of Community Health Nursing: A Phenomenological Study of the Perceptions of Community Health Nurses". I understand that the purpose of this study is to describe what community health nurses value about community health nursing. Beverly Leipert, the investigator of this study and a candidate in the Masters of Science in Nursing Program at the University of British Columbia, has explained the study to me.

I understand that the study will involve two interviews that will last approximately one hour each, and possibly a third interview that will last one half hour. During each of these audiotaped interviews, I will be asked questions about my perceptions of the value of community health nursing. I understand that I can request that the tape or any portion of the tape be erased at any time during the interviews. I understand that I can refuse to answer any questions during the interviews and that I can withdraw from the study at any time. If I withdraw from the study, I will not suffer any personal or professional repercussions. My name and any identifying information will not be revealed in any way in transcriptions of the tapes made during the course of the study or in reports of the study.

I understand that the only people who might listen to the tapes will be Beverly, her thesis advisors, and a professional secretary who may transcribe the tapes. All tapes and transcripts will be stored in a secure location and the tapes will be erased at the completion of the study.

I acknowledge that the study has been adequately explained to me by Beverly Leipert, and that I may contact her at 876-2803 if I have further questions regarding this study. I may also contact Beverly's thesis advisor, Ray Thompson, at 822-7454 if I have questions about the study. I have a copy of the 'Information Letter to Community Health Nurses' and of the 'Consent to Participate' forms.

Signature

Date

Witness

Date 


\section{Appendix C}

\section{Trigger Questions}

1. Based on your experiences and perceptions, what do you value about community health nursing? What in your experience has led you to this position?

2. Based on your experiences and perceptions, how do others value community health nursing? For example:

1. other community health nurses,

2. nurses who do not work in community health,

3. nurse educators,

4. nurse administrators,

5. nurse researchers, and

6. the Canadian public?

What has caused you to have these perceptions?

3. Would you like to add anything further about the value of community health nursing? 